Running head: EMERGENCE OF TEAM RESILIENCE

\title{
The Emergence of Team Resilience: A Multilevel Conceptual Model of Facilitating Factors
}

Daniel F. Gucciardi ${ }^{1}$, Monique Crane ${ }^{2}$, Nikos Ntoumanis ${ }^{3}$, Sharon K. Parker ${ }^{4}$, Cecilie ThøgersenNtoumani $^{3}$, Kagan J. Ducker ${ }^{1}$, Peter Peeling ${ }^{5}$, Michael T. Chapman ${ }^{1}$, Eleanor Quested $^{3}$, and Philip Temby $^{6}$

${ }^{1}$ School of Physiotherapy and Exercise Science, Curtin University

${ }^{2}$ School of Psychology, Macquarie University

${ }^{3}$ School of Psychology, Curtin University

${ }^{4}$ Curtin Business School, Curtin University

${ }^{5}$ School of Human Sciences, The University of Western Australia

${ }^{6}$ Land Division, Defence Science and Technology Group

\section{Author Notes}

*Address correspondence to Daniel Gucciardi, School of Physiotherapy and Exercise Science, Curtin University, GPO Box U1987, Perth, Australia, 6845. Email: daniel.f.gucciardi@ gmail.com Funding statement: The Commonwealth of Australia supported this research through the Australian Army and a Defence Science Partnerships agreement of the Defence Science and Technology Group, as part of the Human Performance Research Network. Daniel Gucciardi was supported by a Curtin Research Fellowship; Sharon Parker was supported by an ARC Laureate Fellowship (FL160100033).

Accepted for publication $31^{\text {st }}$ July 2018: Journal of Occupational and Organisational Psychology 


\begin{abstract}
With empirical research on team resilience on the rise, there is a need for an integrative conceptual model that delineates the essential elements of this concept and offers a heuristic for the integration of findings across studies. To address this need, we propose a multilevel model of team resilience that originates in the resources of individual team members and emerges as a team-level construct through dynamic person-situation interactions that are triggered by adverse events. In so doing, we define team resilience as an emergent outcome characterised by the trajectory of a team's functioning, following adversity exposure, as one that is largely unaffected or returns to normal levels after some degree of deterioration in functioning. This conceptual model offers a departure point for future work on team resilience and reinforces the need to incorporate inputs and process mechanisms inherent within dynamic interactions among individual members of a team. Of particular importance is the examination of these inputs, process mechanisms and emergent states and outcomes over time, and in the context of task demands, objectives and adverse events.
\end{abstract}

\title{
Practitioner Points:
}

- Team resilience as a dynamic, multilevel phenomenon requires clarity on the individual- and team-level factors that foster its emergence within occupational and organisational settings

- An understanding of the nature (e.g., timing, chronicity) of adverse events is key to studying and intervening to foster team resilience within occupational and organisational settings

Keywords: coordination; human capital; input-process-output; leadership; team dynamics; team identity; work design 


\section{The Emergence of Team Resilience: A Multilevel Conceptual Model of Facilitating Factors}

Adversity is common across most, if not all, occupational settings, whether it is a disaster management team having to deal with the effects of an aftershock in response to a major earthquake, a surgical team needing to operate immediately after having had a patient die, or a military unit being ambushed and outnumbered by enemy forces. The notion that teams have the collective capacity to withstand or recover from adverse events that threaten their functioning, viability or development, that is, demonstrate team resilience, has intuitive and practical appeal. However, in contrast to the rich literature on individual resilience that spans nearly five decades (for reviews, see e.g., Kossek \& Perrigino, 2016; Pangallo, Zibarras, Lewis, \& Flaxman, 2015), research on team resilience has gained momentum only over the past decade (e.g., Alliger, Cerasoli, Tannenbaum, \& Vessey, 2015; Gomes, Borges, Huber, \& Carvalho, 2014; Savioja, Norros, Salo, \& Aaltonen, 2014; Sharma \& Sharma, 2016). A key conclusion from this work is that the literature on team resilience is hampered by piecemeal theoretical development, conceptual ambiguity (e.g., resilience-enhancing resources that are assumed to predict resilient outcomes), and methodological weaknesses (e.g., reliance on cross-sectional snapshots of static associations and retrospective interviews) that render existing work inadequate for advancing theory and informing practice. To help spawn a new era of theory and research on team resilience, scholars would benefit from a conceptual model that integrates and provides clarification on substantive perspectives (e.g., common definition, core elements) in a way that embraces the dynamic features of this concept. The availability of a unifying framework and conceptual clarity has the potential to foster systematic, coordinated, and accumulative efforts to studying and theorising about team resilience.

Our goal in this paper is to propose and articulate the key features of a multilevel model of team resilience emergence that can provide a conceptual foundation upon which researchers can test theoretical propositions in future research. In so doing, we draw attention to the what (i.e., inputs, processes, states, and outcomes), how (i.e., relations among key concepts), and why (i.e., underlying rationales) of team resilience in a way that provides sufficient guidance for future work, 
yet is flexible enough to permit specific hypotheses based on the organisational context in which that research is conducted (Cornelissen, 2017). We begin with a brief primer of individual resilience, followed by an overview of research and theory on team resilience. We next provide the working definition of team resilience that underpins our conceptual model. Our attention then turns to our proposed conceptual model of team resilience, including a description of the key propositions that are at the core of this dynamic and multilevel framework. We close the paper by sketching methodological considerations for the study of team resilience emergence.

\section{From Individual to Team Resilience}

The concept of resilience has a central focus on what enables a system (e.g., individual, family, community) to resist or bounce back from adverse events or stressors that threaten its functioning, viability or development (Masten, 2014). Given the complexities of life in modern society, it is unsurprising that the concept of individual resilience has garnered a substantial and rich body of work over the past 50 years (e.g., see Becvar, 2013; Goldstein \& Brooks, 2013; Reich, Zautra, \& Hall, 2010). This work has focused on understanding resilience as a trait (i.e., fixed attribute of individuals), capacity (i.e., contextually salient and malleable), or process (i.e., experiencing positive outcomes following exposure to an adverse event). There are strengths and weaknesses to each of these perspectives (for reviews, see Fletcher \& Sarkar, 2013; Kossek \& Perrigino, 2016). Briefly, although there may be some universalities with regard to protective resources or resilience-enhancing factors (e.g., mastery motivation, self-regulation), ultimately, what works best will depend on individuals and the situation or context in which they are embedded (e.g., risk type, developmental period, culture; Southwick, Bonanno, Masten, Panter-Brick, \& Yehuda, 2014). As such, generalising findings from one context (e.g., growing up in poverty) to another (e.g., disaster management) is fraught with danger because it is important to understand the personal and contextual factors that make a difference within the confines of the salient situational demands, particularly with regard to the nature of the adversity experienced. 
Relative to the work on individual resilience, there has been little systematic empirical research and theorising on resilience among teams to date. In terms of peer-reviewed publications on team resilience, 18 papers were identified in a recent narrative review of the literature, with the earliest research published in 2009 (Morgan, Fletcher, \& Sarkar, 2017). Briefly, scholars have examined a variety of determinants, mechanisms and outcomes of team resilience across a range of settings, including but not limited to sport (e.g., Morgan, Fletcher, \& Sarkar, 2013), business (e.g., Meneghel, Martínez, \& Salanova, 2016), information technology (e.g., Sharma \& Sharma, 2016), natural and nuclear power industries (e.g., van der Beek \& Schraagen, 2015), and military (e.g., Mjelde, Smith, Lunde, \& Espevik, 2016). The majority of this empirical work has relied on static methodologies (e.g., cross-sectional surveys, one-off retrospective interviews) that represent a mismatch between method and theory on resilience (Bonanno, Romerso, \& Klein, 2015; Luthar, Cicchetti, \& Becker, 2000; Masten \& Narayan, 2012). Field and laboratory-based simulation studies (e.g., Gorman et al., 2016; Savioja et al., 2014) have alleviated such concerns by providing insight into complex dynamic person-situation interactions over time that are essential to an understanding of team resilience. Finally, one intervention study to date has tested directly transformational leadership as a key determinant of team resilience by examining the effects of a training package designed to foster resilient behaviours among team members on team performance prior to and after exposure to an adverse event (van der Kleij, Molenaar, \& Schraagen, 2011).

Scholarly interest has also encompassed conceptual expositions where scholars have discussed a broad range of individual-, team- and system-level factors considered central to the conceptualisation and assessment of team resilience (Alliger et al., 2015; Duff, Del Guidice, Flint, Nguyen, \& Kudrick, 2014; Rodríguez-Sánchez \& Perea, 2015). In their narrative synthesis, Bowers, Kreutzer, Cannon-Bowers, and Lamb (2017) forwarded the idea of team resilience as a secondorder emergent state that transmits the effects of lower-order emergent states such as cohesion, collective efficacy and adaptability into valued outcomes for the team. Bowers et al. identified a range of individual, team and organisational level factors that serve as inputs (e.g., optimism, 
norms, diffused power), processes (e.g., cognitive restructuring, leadership, information sharing), or outcomes (e.g., psychological health, error avoidance, goal attainment) of team resilience. The multilevel, dynamic, and emergent nature of team resilience as well as the specification of a detailed list of inputs, processes, and outcomes represent important strengths of this conceptual piece. Nevertheless, two key limitations of this proposal require extension in future theorising about team resilience. First, the complex interactions among the inputs, processes and outcomes requires clarification. For example, various individual-level traits were identified as important inputs into the emergence of team resilience, yet it remains unclear what factors are important, and when and how they generate and sustain emergence processes and outputs. Second, the nature of team resilience as a second-order emergent state is largely undefined, other than to say that it is "the result of a number of team actions or processes, rather than a process in it of itself' (Bowers et al., 2017, p. 9). In other words, what is the form of the team resilience construct that emerges from the interaction among inputs and processes to the system? Emergent constructs can range from compilation (i.e., divergence) to composition (i.e., convergence) and are essential information to any theory of emergence (Kozlowski, Chao, Grand, Braun, \& Kuljanin 2013).

In sum, although there are disparate perspectives, a common theme among past conceptual and empirical work is the conceptualisation of team resilience as a dynamic concept that emerges over time, and which cycles and fluctuates through the interaction of individual, contextual, and team level factors (see also Bowers et al., 2017; Kennedy, Landon, \& Maynard, 2015). As such, a group of resilient individuals does not always result in a resilient team. Resilient individuals, for example, may cope with adversity in ways that are effective for their individual performance and functioning but are detrimental to the structures and processes of the team. In this sense, team resilience is affected by factors that exist prior to group formation and which are established during group transactions over time within the context of situational factors. Cognisant of this conceptual thread among existing work to date, it is important that any conceptual model of team resilience encompass its multilevel and dynamic nature. With the exception of Bowers et al. (2017), none of 
the existing conceptual models provides a comprehensive exposition of the dynamic, multilevel and emergent nature of team resilience. However, although Bowers et al.'s conceptual exposition offered a comprehensive list of potential inputs, processes, emergent states, and outcomes of team resilience (i.e., the 'what' question), it requires clarification and extension to shed light on the relations among these key factors (i.e., the 'how' question) and the underlying rationales (i.e., the 'why' question). These missing pieces in the scholarly literature - referred elsewhere as a "complication... of the academic conversation" - motivate our current article (Lange \& Pfarrer, 2017, p. 408). In essence, whereas Bowers et al. provided a list of candidate ingredients, we propose a recipe for team resilience emergence that can be examined empirically in future research.

We take a pragmatic approach to theorising about team resilience emergence via abductive reasoning to shed initial light on the what, how and why questions (Shepherd \& Suddaby, 2017). Drawing from multilevel theory (Kozlowski \& Klein, 2000; Kozlowski et al., 2013), and integrating ideas or empirical evidence from distinct yet related literatures (e.g., human capital resources, situation awareness, leadership), we propose a conceptual model of team resilience that originates in the resources of individuals and emerges as a collective state or outcome through dynamic person-person and person-situation interactions that are triggered by adverse events (see Figure 1). Emergence encompasses a dynamic process whereby interactions among lower-level units over time coalesce or diverge to create a new, collective entity at higher levels (Fulmer \& Ostroff, 2016; Kozlowski et al., 2013). The outcome of this interactive process among lower-level units is referred to as an emergent construct (Kozlowski \& Klein, 2000). In so doing, our conceptual model and propositions serve as guideposts for future research, rather than testable or falsifiable hypotheses regarding the relations among constructs (Cornelissen, 2017). This approach is consistent with the essence of the interactionist perspective of resilience proposed by leading scholars (Southwick et al., 2014). In other words, it makes sense to have at our disposal a model in which context-specific hypotheses can be integrated and cumulated over time because what works best will depend on individual teams and the situations in which they are embedded. 
By connecting distinct yet related literatures on individuals (e.g., human capital resources) and teams (e.g., shared mental models) with multilevel theory, our conceptual exposition of team resilience emergence offers four important contributions to the literature. First, we articulate a conceptual blueprint of the what, how, and why of team resilience emergence that can guide empirical tests in future research, yet we do so in a way that embraces flexibility rather than prescription. For example, rather than prescribe a single grouping of human capital resources that maximise the likelihood of team resilience emergence, we embrace the notion of, and provide guidance for, the identification of individual-level factors that are configured to optimise salient team-level processes and outcomes. This first contribution is important because it will shift the focus from identifying potential ingredients to considering how and why these elements might be integrated as part of a recipe for team resilience emergence. Second, we conceptualise team resilience in a way that integrates distinct yet complementary perspectives of resilience as a trait, capacity, process, or outcome in one unifying framework. Specifically, rather than conceptualising team resilience as either a trait, capacity, process, or outcome, our model explains how each of these components feed into the emergence of team resilience. This contribution has the potential to resolve existing debates regarding the definition and conceptualisation of team resilience. Third, we conceptualise adversity as the primary catalyst for the emergence process and, in so doing, underscore the importance of time (i.e., temporal considerations) for theory and research on team resilience. Essentially, it is only within the context of adversity that teams can exhibit their resilience, and scholars can evaluate the salience of inputs and processes that shape team resilience emergence. This contribution is important because past research and theory on team resilience is often silent on these temporal influences. Fourth, we provide clarity with regard to critical conceptual and methodological issues that have the potential to inform a new wave of research on team resilience. For example, we underscore the centrality of adversity to theorising about and studying team resilience, such that we can determine team resilience emergence as a higher-level 
state or outcome only in response to an adverse event. This final contribution is important because it will maximise synergies between concepts and methods in future research on team resilience.

\section{Defining Team Resilience}

Concept definitions are at the heart of any model or theory. Scholars have proposed several definitions of team resilience over the past decade (for reviews, see Flint-Taylor \& Cooper, 2017; Morgan, Fletcher, \& Sarkar, 2017). However, as there is no commonly agreed upon definition of team resilience, such disparity has the potential to thwart consistencies in operationalisation and cumulative progress of research and theory on this concept. The modal definition within the literature is that forwarded by West, Patera, and Carsten, 2009 (2009), who defined team resilience as the team's “capacity to bounce back from failure, setbacks, conflicts, or any other threat to wellbeing that they may experience" (p. 253). From this perspective, team resilience is concerned primarily with the inputs or factors that exist within the group from the outset; however, there is little clarification on the sources of those inputs (e.g., individual, team, organisational) within this definition or its underlying description (see also Alliger et al., 2015). The definition of team resilience proposed by Morgan et al. (2013) is also adopted commonly within the literature; they defined team resilience as "a dynamic, psychosocial process which protects a group of individuals from the potential negative effect of stressors they collectively encounter. It comprises of processes whereby team members use their individual and collective resources to positively adapt when experiencing adversity" (p. 552). The focus in this definition is one of team resilience as a process by which teams deal with stressors or adversities that are experienced as a collective through dynamic interactions among individual members. Although this definition provides clarity on the inputs and dynamic processes of team resilience, it bears a striking resemblance to the related construct of team adaptability, for which a substantial body of work exists (for reviews, see Christian, Christian, Pearsall, \& Long, 2017; Maynard, Kennedy, \& Sommer, 2015). We describe the distinctions between team resilience emergence and team adaptability later in this manuscript. 
In taking stock of past work, and guided by recommendations for high quality concept definitions (Podsakoff, MacKenzie, \& Podsakoff, 2016), we conceptualise team resilience as an emergent outcome that reflects a compilation form of emergence. From this perspective, team resilience is best viewed as an outcome that emerges over time via dynamic person-situation interactions, rather than a trait, capacity or process. Formally, team resilience as an emergent outcome characterises the trajectory of a team's functioning, following adversity exposure, as one that is largely unaffected or returns to normal levels after some degree of deterioration in functioning. As detailed in Table 1, we consider team resilience as an emergent outcome to be characterised by several necessary and sufficient conditions. Specifically, these conditions characterise the "properties...that all exemplars of the concept must possess [necessary]...[and] things that only exemplars of the concept possess [sufficient]" (Podsakoff et al., 2016, p. 181). Thus, team resilience is characterised by the joint combination of six key conditions.

Aligned with past work on resilience (e.g., Bonanno, Westphal, \& Mancini, 2011; Layne, Warren, Watson, \& Shalev, 2007; Norris, Tracy, \& Galea, 2009), we propose three broad possible trajectories for teams that may follow exposure to an adverse event. In the first trajectory, termed resistance trajectory, team functioning remains relatively unaffected (i.e., disruption to the system is minimal) in that there is little variability in team functioning post-adversity relative to baseline levels. A second trajectory, termed the bounce back trajectory, is characterised by initial negative effects of the adverse event (e.g., substantial decrease in performance indices), followed quickly by recovery to competent functioning within a timeframe that is salient with regard to key contextual factors (e.g., nature of the task, type of objective). In the third trajectory, which we term recovery trajectory, deterioration in functioning lasts for some period of time (e.g., several weeks or months) and is followed by a return to competent functioning gradually over time. These three types of trajectories provide a general sketch of the heterogeneity of team functioning in response to an adverse event, relative to the level of functioning prior to their exposure to the adversity. The notion of "relative to prior levels of functioning" is a critical consideration for the science of team 
resilience emergence because this information provides an important context upon which to operationalise these trajectories of team performance. As such, we need to know the objective(s) of the team to identify salient indicators and degrees of functioning within that context.

Considering these trajectories as endpoints or outcomes suggests that team resilience emerges as a compilation construct. Specifically, divergent interactions among individual members within the confines of task demands, and the nature of the adverse event, lead to the integration of unique human capital resources in ways that create a pattern or configuration (Kozlowski \& Klein, 2000). This form of emergence is analogous to a puzzle, where the individual pieces represent unique human capital resources of individual members that fit together to generate an overall picture that makes sense (Kozlowski \& Chao, 2012). This definition of team resilience and underlying conceptual model explained in detail below differ from and therefore extend past conceptual work in two important ways. First, as is explained in further detail below, underpinning our definition is the conceptualisation of team resilience as a team-level outcome that emerges from different combinations of individual members' human capital resources and their interaction over time. In this way, our conceptual model encompasses how team resilience as an emergent outcome is shaped by traits, capacities, and processes in one unifying framework. Second, in clarifying our definition of team resilience as a team-level outcome, we make it explicit in our underlying conceptual model that three broad trajectories of a team's functioning can occur following exposure to an adverse event, whereas past work has focused only on one (Morgan et al., 2013; West et al., 2009) or two (Alliger et al., 2015; Morgan et al., 2013) of these possible pathways.

\section{Operationalising Team Resilience}

The notion of functioning is central to our definition of team resilience, which raises a question as to how such a concept might be operationalised. At the individual-level, when resilience is conceptualised as a return to normal functioning despite adversity or risk factors that threaten well-being, functioning has typically been assessed in two main ways. First, early research on resilient functioning among children considered the child's ability to meet expected milestones 
despite risk, such that the child is developing or performing at age and culturally appropriate levels (e.g., Masten et al., 1999). Secondly, the observation of resilience has been characterised as the absence of symptoms of mental illness after a potentially traumatic event or adversity that places the individual at risk as a primary indicator of functioning (e.g., Butler et al., 2009). When it comes to team resilience, how can functioning be characterised best? This question is critical to the conceptualisation and operationalisation of team resilience because a return to normal team functioning following adversity exposure is of central importance.

Given that teams exist primarily for the purpose of attaining a common and valued objective (Kozlowski \& Ilgen, 2006; Sundstrom, de Meuse, \& Futrell, 1990), we propose that the outcome of team performance is the most salient and pragmatic measure of functioning. As such, we conceptualise team resilience functioning as team performance outcomes after exposure to an adverse event relative to levels of functioning prior to that adversity. In this sense, we are concerned primarily with team performance trajectories, that is, patterns of performance over a specific temporal period in which the team has encountered some type of adverse event. Team performance outcomes are often operationalised through indicators of quantity (e.g., team wins over a competitive season), quality (e.g., team disposal efficiency), effectiveness (e.g., team sales in offpeak season) or efficiency (e.g., time taken to complete required tasks) ${ }^{1}$.

Our focus on team performance as the primary indicator by which to infer team resilience emergence represents an important distinction from past work on individual resilience where health and well-being (e.g., quality of life, affect, stress biomarkers) outcomes are typically prioritised (e.g., Leppin et al., 2015; Robertson, Cooper, Sarkar, \& Curran, 2015). For individual resilience, the salience of an indicator of positive functioning is contingent upon the type of adversity experienced and the potential effects on psychological, social or physical health, relative to the developmental

\footnotetext{
${ }^{1}$ At the individual level, the extent to which resilience is present or displayed across multiple life domains is best conceptualised as differing in degrees (Pietrzak \& Southwick, 2011). For example, someone who manages stress well at work may do so at the cost of functioning in personal relationships. A similar argument could be made for work teams in that performance indices support an interpretation of team resilience, yet other metrics (e.g., psychological and emotional well-being of members) are compromised.
} 
stage of the person (Luthar et al., 2000; Southwick et al., 2014). For example, social connectedness might be an appropriate indicator of positive adaptation or functioning for an adolescent who has relocated to a new country with her family, whereas the absence of, or minimal re-experiences of a traumatic event (e.g., nightmares, flashbacks) might be a salient indicator of functioning for an adult who witnessed a serious crime (e.g., murder). Resilient outcomes at the individual level, therefore, are heterogeneous and almost all encompassing across biological (e.g., cortisol), physical (e.g., muscle strength), emotional (e.g., positive or negative affect), behavioural (e.g., school attendance), cognitive (e.g., standardised aptitude test), social (e.g., family cohesion), or community (e.g., healthcare utilisation) systems. The diversity and breadth of resilient outcomes is unsurprising because the exact nature of functioning is often absent or assumed rather than described explicitly in definitions of individual resilience (for a review of definitions, see Fletcher \& Sarkar, 2013).

In contrast to the focus on the nature of the adversity for individual resilience, we clarify this conceptual feature by contextualising our conceptualisation of team resilience emergence with regard to the underpinning purpose of the system; that is, two or more individuals with unique yet interdependent roles and responsibilities who are brought together to achieve a common objective that is salient to the organisation in which they are embedded (Kozlowski \& Ilgen, 2006). For this reason, we suggest that the extent to which teams meet the performance standards (e.g., efficiency, effectiveness) of the task is the primary criterion by which to assess functioning. Team performance is part of team effectiveness (Kozlowski, 2018), yet the unique feature for team resilience emergence is the trajectory of functioning within the context of adversity. Nevertheless, it is important to acknowledge that team outcomes broadly are characterised by team performance, the degree to which members' needs are achieved (satisfaction), and members' willingness to remain in the team (viability; Hackman, 1987). Satisfaction and/or viability are important targets for organisations (e.g., employee turnover rates; Park \& Shaw, 2013), yet inevitably the degree to which a team meets the performance standards of a task will be the primary criterion by which organisations assess the effectiveness of teams and therefore their contributions to the organisation. 


\section{Distinctiveness of Team Resilience}

It is also important to consider how our definition of team resilience differs from the related constructs of team adaptability and social resilience. Clarifying the distinction between team resilience and team adaptability is crucial, as notions of adaptability are central to past work on team resilience (e.g., Edson, 2012; Morgan et al., 2013; van der Beek \& Schraagen, 2015) and formative work on resilience (e.g., Luthar et al., 2000; Masten, 2014). These definitions of resilience share conceptual overlap with the concept of adaptation, which for teams is conceptualised across three components including inputs (i.e., capacity to alter or change team processes in response to stimuli or triggers; e.g., cognitive ability, personality), processes (i.e., enacting alterations or changes in team processes; e.g., monitoring progress, interpersonal dynamics), and outcomes (i.e., cognitive, emotional and behavioural results of the enacting changes in team processes; e.g., team performance, cohesion) (Maynard et al., 2015). Change is central to the conceptualisation of team adaptation across each of these components in that teams make cognitive, affective, and behavioural modifications in response to internal (e.g., roles, composition) or external (e.g., task environment) stimuli that can be temporary or enduring in duration (Christian et al., 2017). Team adaptation is best conceptualised as the adjustments or modifications teams make in response to changes in the internal or external environment and, therefore, is characterised by the processes by which inputs into the system translate into adaptive outcomes for the team.

There are two important distinctions between our definition of team resilience and that of team adaptation. The first distinction relates to the conceptual theme of each concept. Although both concepts can be positioned across each of the layers of the input-mediator-output-input framework (IMOI; Ilgen, Hollenbeck, Johnson, \& Jundt, 2005), they differ in terms of their core conceptual theme. Specifically, the fundamental attributes of team adaptation relate to the modifications teams make in response to some type of stimuli (i.e., process), whereas team resilience is concerned with the outcome of the dynamic interaction among the inputs and their influence on unfolding processes over time (i.e., output). In other words, team adaptation is 
observed via enacted or emergent modifications to team processes or mediators during or following some type of change (Christian et al., 2017). In contrast, team resilience is inferred as an emergent construct via assessments of the performance trajectory prior to and after an adverse event through objective (emergent outcome, e.g., quality, efficiency) or subjective (emergent state, i.e., shared perception of team's capability to deal with adversity) indicators. Thus, team adaptation involves modifications to team processes following some type of change - which could involve negatively (e.g., equipment malfunction) or positively valenced events (e.g., new opportunities in the environment) - that result in a broad range of possible emergent outcomes (e.g., trust, cohesion); one of which is returning to competent levels of functioning following adversity or withstanding the maladaptive effects of adversity.

The second distinction between team resilience and team adaptation relates to the outcomes that arise from the dynamic interactions among team members. Like scholars who have investigated team adaptability inputs, adaptation processes, and adaptive outcomes (Christian et al., 2017; Maynard et al., 2015), team performance is central to our model of team resilience. However, whereas team adaptive outcomes are operationalised in terms of performance indices after some type of trigger event (Christian et al., 2017), we conceptualise functioning for team resilience in terms of the performance trajectory over time, that is, post-adversity performance relative to preadversity performance. We describe below three broad possible trajectories of team functioning that may follow exposure to an adverse event as a key proposition of our model of team resilience. In contrast, the outcomes of team adaptation can be assessed in terms of performance indices during or following change that occur because of cognitive, affective, and behavioural modifications to team processes. By way of example, consider a team that adjusts their communication approach in response to some type of stimuli (i.e., team adaptation); these modifications may enable that team to maximise decision-making effectiveness during task execution and, in turn, achieve the target goal (i.e., team adaptive outcome). However, this adaptive outcome tells us little about the resilience of the team unless we consider this performance outcome in relation to the team's functioning prior to 
the adverse event, such that we have a temporal understanding of the pattern of performance in terms of resisting, bouncing back, or recovering from adverse events.

The distinction between team resilience emergence and social resilience is another important consideration because both concepts involve two or more people engaged in some type of relationship. Of particular relevance for this distinction is our conceptualisation of functioning for team resilience emergence as one that is characterised by team performance outcomes. Social resilience is defined as "the capacity to foster, engage in, and sustain positive relationships and to endure and recover from life stressors and social isolation" (Cacioppo, Reis, \& Zautra, 2011, p. 44). Defined in this way, social resilience is concerned primarily with meaningful relationships and social engagements, such that the defining feature is an individual-level sense of connectedness with others. This conceptualisation of social resilience differs to that of team resilience, which is underpinned by interdependent goal-directed behaviour and, therefore, team performance is the ultimate endpoint. Thus, although team and social resilience both are inherently multilevel in nature (i.e., individual level, interpersonal, and collective resources), they differ in how functioning is operationalised and therefore what types of indices provide evidence for the degree to which the concept has been observed or occurred within individuals or groups of people.

\section{Model Overview and Key Propositions}

The IMOI framework (Ilgen et al., 2005) provides a useful basis upon which to set the scene for our conceptual model of team resilience. Inputs refer to existing factors of individuals (e.g., personality), the team (e.g., formation), and the context (e.g., work design) that shape and constrain interactions among individuals. Mediators refer to the ways by which inputs are combined and transformed into outcomes through dynamic interactions among team members (e.g., coordination among team members). Outcomes represent valued results (e.g., performance) or consequences (e.g., commitment) of team interactions geared towards a common objective. We conceptualise team resilience as a team-level outcome that originates from the resources of individuals (propositions 1-2) and emerges via dynamic interactions among team members (propositions 3-8). 
Adhering to the principles of conceptual parsimony (e.g., Giere, 2004), our focus is on the most fundamental inputs and processes of a theory of team resilience emergence, even though the number of possible factors needed to explain fully this emergent construct is likely to be large (e.g., see Bowers et al., 2017). We focus on individual- and team-level factors in this conceptual exposition and exclude explicit reference to organisational influences because the empirical literature on organisational-level inputs into team resilience is insufficiently developed to generate precise propositions regarding such influences (Maynard \& Kennedy, 2016). Others have drawn from research concerned with organisational resilience and extrapolated this knowledge to the teamlevel with limited empirical or conceptual justification (for a review, see Bowers et al., 2017); however, there is danger in assuming relations among inputs, processes, and outcomes are consistent at different levels and therefore isomorphic (Rousseau, 1985). In other words, what makes an organisation resilient might not be the same as what makes a team resilient. The inclusion of specific assertions regarding the causal dimensions of team resilience emergence provides a conceptual template to guide the articulation of testable and falsifiable hypotheses in future work (Trafimow, 2009). In the following sections, we unpack these details of our conceptual model to provide clarity on the inputs, processes and outcomes of team resilience. We focus on those aspects that facilitate the emergence of team resilience, and therefore this conceptual exposition excludes a consideration of aspects that might undermine it (e.g., narcissism, rivalry, conflict).

\section{Proposition 1}

Team resilience emerges from combinations of human capital resources of individual members that are relevant to team objectives. As teams are in essence goal-directed entities, we contend that the roots of team resilience are founded in the capacities of individuals or their potential for action towards an objective (Ployhart, Nyberg, Reilly, \& Maltarich, 2014). This perspective is consistent with past conceptual and empirical work in which team resilience has been defined or conceptualised as an input into the system, that is, an existing capacity of the team to act in purposeful ways during and in responding to adverse events (e.g., Alliger et al., 2015; West et al., 
2009). A capacity in this sense is rooted in the human capital resources of individuals, which are "based on individual KSAOs [knowledge, skills, abilities, and other characteristics] that are accessible for unit-level purposes" (Ployhart et al., 2014, p. 374). Key here is that these individuallevel inputs are salient for team resilience emergence only when they are relevant to the task, objective, and/or contextual circumstances confronted by the team (Barney, 2001). For example, in the military context, skills in close quarter fighting would be considered a human capital resource for infantry soldiers conducting ground combat missions involving significant threat (e.g., clearing enemy compounds), but less so for another group of infantry soldiers conducting humanitarian missions in a relatively benign environment (e.g., cleaning up a small town that has been hit by a flood). As such, information regarding the nature of the task, objective, and/or adversity is required to ascertain the degree to which an individual-level KSAO is considered a human capital resource.

The centrality of context to this proposition does not preclude the likelihood of salient human capital resources for team resilience that generalise across situations or occupational contexts because they share the conceptual theme of maximising efforts to resist, bounce back, and recover from adverse events. Conceptual and methodological reviews of existing measures of individual-level resilience suggest a core group of resources, including self-efficacy, active coping, positive emotions, mastery, hardiness, and adaptability (e.g., Pangallo et al., 2015; Windle, Bennett, \& Noyes, 2011). Nevertheless, there is the possibility that conclusions drawn from research on individual-level resilience, grounded largely in work on children who were exposed to systemic adversities during childhood, may not generalise to other systems including teams (Rousseau, 1985). Generalised self-efficacy as a human capital resource is common to most measurement approaches of team resilience to date (e.g., Sharma \& Sharma, 2016; West et al., 2009). However, owing to the reliance on cross-sectional designs in past work, the resilience-enhancing nature of this resource for dealing with adversity is assumed rather than tested directly. Cognitive appraisals of situational demands against one's available resources to cope are central to the stress response, such that contextual demands can be perceived as a threat (demands outweigh available resources) or 
challenge (available resources outweigh demands) (Blascovich, \& Tomaka, 1996; Seery, 2013). Such appraisals are critical when confronted with potentially stressful situations because they can affect physiological, psychological, and behavioural responses in ways that are either adaptive or maladaptive for functioning (e.g., Jamieson, Mendes, Blackstock, \& Schmader, 2010; Jamieson, Mendes, \& Nock, 2013). Consideration of the nature of the task, objective, and/or adversity is central to understanding the salience of a human capital resource for team resilience, yet by studying a broad range of contexts we expect that some but not all resources will generalise.

A novel feature of our conceptual model of team resilience is the acknowledgment of essential structural dynamics among multiple inputs into the system. Specifically, because individuals have multiple KSAOs (Murphy, 2012), it follows that there are diverse combinations of human capital resources that can shape team resilience emergence (Ployhart et al., 2014). Diversity in a system is important because it underpins the capability to deal with adverse events; put simply, "more tools imply more responses" (Page, 2014, p. 276). Of central importance to our conceptual model is the combination of heterogeneous resources within a system in ways that are complementary and therefore maximise or enhance their overall value (Ennen \& Richter, 2010). In other words, team resilience emergence depends on specific configurations of human capital resources and their complementarity or fit among individual members within the context of situational demands. For example, instructions from a military tank commander to a team member (e.g., driver, gunner) are unlikely to yield high performance, especially in the heat of battle, unless this information is complemented by a driver or gunner who is skilled enough to execute those instructions. This expectation is consistent with an interactionist perspective whereby resilience represents the interaction between individuals and their environment (Rutter, 2006). Within the context of team resilience, the joint deployment of two or more resources is not complementary per se, but instead relies on their salience for goal-directed activities of a particular team (e.g., execution of a task). Aligned with the concept of equifinality (i.e., multiple pathways to the same 
end state), we propose that team resilience emergence relies on multiple successful combinations of human capital resources, rather than on any one single package.

Human capital resources may be combined interactively or causally through sequential interdependence within or across levels of a system (Ployhart et al., 2014). Interaction complementarity occurs when the benefits of one resource are enhanced through its combination with one or more other resources, such that the outcome of their integration is different to that which would occur when each resource is deployed independently (Adegbesan, 2009). For example, the joint deployment of one member's problem-solving capabilities and another member's conscientiousness has the potential to foster efficient and effective task execution and, therefore, maximise value for team performance in ways that are more beneficial than the application of these resources in isolation. The key element here is the degree of fit or congruence between the resources deployed and contextual factors (Ennen \& Richter, 2010). In the case of causal complementarity, one resource facilitates the acquirement of new resources, or augments an existing resource. Within the context of soccer, for example, the advantages of a winger who is skilled at delivering long range passes (i.e., cross) into the box with precision can be capitalised by the strengths of a powerful striker who has exceptional 'heading' abilities, particularly during situations in which the team is a player down (e.g., red card). As such, information regarding the interplay of individual members and the demands of the situation is required to ascertain the degree to which an individual-level KSAO is considered a human capital resource for the team in a specific context.

Given the complexities of multilevel phenomena (Kozlowski \& Klein, 2000; Kozlowski et al., 2013), and in particular the importance of temporal dynamics for understanding teams (Gully, 2000), it is difficult to offer precision regarding combinations of human capital resources that underpin the emergence of team resilience as an outcome (performance) or state (shared perceptions among team members), and generalise across teams, tasks, and contexts. Nevertheless, the literature on team composition provides guidance for the identification of individual-level factors that might be configured to optimise salient team-level processes and outcomes. Mathieu, Tannenbaum, 
Donsbach, and Alliger (2014) described four broad models and formulas and their integration to encapsulate the key dimensions of each characterisation (see Table 2). First is the traditional personnel-position fit approach in which individual human capital resources are aligned with the specifics of a position or role, typically with little consideration of the context or member dynamics (i.e., who is the best person for this job or position?). Second is the personnel model with teamwork considerations, where the individual focus on roles or positions in the traditional model is extended to encompass generic team-level KSAOs possessed by members and their relative importance to key task(s). Third is the team profile model in which individuals' human capital resources are considered collectively in terms of how their compositional distribution across the team can foster adaptive team processes and outcomes rather than enhance individuals' role or position performances. Fourth is the relative contribution model, where it is acknowledged that some members can exert a disproportionate influence on team effectiveness because of maladaptive individual-level human capital resources (e.g., highly pessimistic), particularly in cases where members occupy a "core" role for team functioning. The integration of these four models offers several important considerations for the identification of human capital resources that are salient for team resilience emergence: (i) the degree of fit between individuals' human capital resources and their specific role or position on the team; (ii) the degree of team-generic KSAOs possessed by individual members; (iii) the relative importance of individual roles or positions for effective collective performance (iv) the linked interdependencies between individual members and their performance contributions; and (v) the relative importance of different team profiles and the contributions of individual members to these collective distributions (Mathieu et al., 2014).

\section{Proposition 2}

\section{Adversity triggers the activation of human capital resources for the emergence of team}

resilience. Adversity is central to all definitions and conceptualisations of resilience (e.g., Kossek \& Perrigino, 2016; Luthar et al., 2000). Adversity is a temporally bound, low-to-moderate probability event external to the perceiver that represents a major assault on the functioning of a system 
(Bonanno, 2004; see also, Morgeson, Mitchell, \& Liu, 2015). When such experiences involve a real or perceived threat to life or limb relating to the self or significant others, they are referred to as traumatic events (American Psychiatric Association, 2013). Adversity is, therefore, a broad concept encompassing a range of experiences that differ in their intensity and duration, including those that are task-based (i.e., the 'doing' part of teamwork such as tasks, tools) and teamwork-based (i.e., the means by which objectives are accomplished such as interpersonal or cognition conflict; Kennedy et al., 2016; Turner, 2016). The distinction between acute (e.g., triggered quickly, short in duration such as equipment malfunction at a critical time) and chronic adversities (e.g., appear slowly over an extended period such as workplace bullying) is important because of their phenomenological differences (e.g., immediate versus delayed effects) and the flow-on effects for resilience processes (Bonanno, 2012; Masten \& Narayan, 2012). As such, the temporal dimension of adversity represents an important boundary condition for team resilience emergence because it provides details on factors that clarify the degree of cross-context applicability or generalisability (Busse, Kach, \& Wagner, 2017). In other words, the temporal nature of adversity represents an important moderating effect within the context of team resilience emergence, such that we expect the salience and magnitude of relations among variables (e.g., which human capital resources foster cognitive coordination) will differ depending on the type of adverse event experienced (e.g., acute versus chronic, experienced by one individual only versus the team as a whole). Where, when, and how these relations differ according to the types of adversities experienced remain important research questions for future empirical work on team resilience emergence.

Adversity is also critical to team resilience emergence because it clarifies when it is applicable and when it is not (Busse et al., 2016; Shepherd \& Suddaby, 2017). Specifically, an adverse event represents the trigger for the emergence process and therefore the boundaries upon which to observe dynamic interactions and potentially maladaptive responses (e.g., cognitions, behaviours) and associated states or outcomes. In other words, adversity sets off in motion the emergence process in which members must individually and collectively access and deploy salient 
human capital resources to minimise the potentially deleterious effects of the contextual demands. Within the context of teams, adverse events may be experienced directly by one or more but not all members, which subsequently has potential flow-on effects for the entire team. Alternatively, all team members may experience the adversity concurrently. As such, the salience of adversity within team resilience emergence differs from that of individual resilience where solely one person experiences an adverse event. Nevertheless, adverse events represent a risk in that they increase substantially the likelihood of negative outcomes with regard to competent functioning of a system (Gest, Reed, \& Masten, 1999). Team resilience as an emergent outcome is inferred or recognised only in relation to adverse events that have the potential to disrupt substantially the functioning of teams when working towards a common objective. Said differently, teams may have as a dormant capacity the necessary inputs to demonstrate resilience, yet without adversity we can never be certain that team resilience has emerged as a higher-level outcome; it is only within the context of adversity that teams can exhibit their resilience in response to the triggering adverse event.

\section{Proposition 3}

Team members must access those human capital resources that are most salient to the triggering event and utilise their situation awareness to deploy them efficiently. Just like knowledge structures (Higgins \& Brendl, 1995), we expect that the accessibility of human capital resources and their salience for a triggering event should determine the extent to which they contribute to team resilience emergence processes, states, and outcomes. Aligned with the conceptualisation of human capital resources as capacities that are available for deployment, individuals must be aware of what is happening in a situation, understand the salience of human capital resources for those contextual demands, and apply them effectively to influence outcomes. For these reasons, the concept of situation awareness is central to team resilience emergence because it relies on individuals' perceptions of what is going on in the environment, the meaningful integration of these dynamic elements, and projection of this information into future goal-directed action (Endsley, 1988). Conceptualised in this way, individual-level situation awareness is 
characterised by ascending levels (perception, comprehension, projection) of internally held knowledge that is salient for the goals or objectives of a specific task (Endsley, 2012).

Raising an individual's situation awareness of how best to exchange that information with other team members is an important regulatory process within the emergence of team resilience. Situation awareness is important because when an adverse event occurs (e.g., spontaneous and acute demands, slowly accumulating forces), there is a requirement for individuals to recognise the need to change course in ways that are salient for the context and nature of the adversity. This aspect of situation awareness relies on explicit knowledge of the task and situation at hand that is available to conscious awareness (Croft, Banbury, Butler, \& Berry, 2004; Endsley, 1997). Yet it is also important to recognise that situation awareness encompasses implicit knowledge that is often unconscious and therefore processed automatically (Lo, Sehic, Meijer, 2014). This automaticity of mental processing is accrued largely through experience as one accumulates numerous encounters with various stimulus-response pairings that are salient to the objectives of the job (Endsley, 1995). As such, situation awareness can serve to catalyse both conscious (explicit) and unconscious (implicit) processes considered central to team resilience emergence. Said differently, we expect individual-level situation awareness to shape the accessibility and activation of salient human capital resources of team members, such that teams who are characterised by a proportion of individual members with higher degrees of situation awareness will be more likely to make optimal use of those inputs into the system in times of adversity.

It is essential that members possess a sufficient degree of situation awareness to enable them to perform their duties effectively, and do so in ways that optimise coordination with other team members and therefore the accomplishment of collective goals (Endsley, 2015). Of critical importance for situation awareness within teams is information exchange between individuals because of its relevance for communicating salient information for collective goal-directed behaviour (e.g., objectives, roles, capabilities; Salas, Prince, Baker, \& Shrestha, 1995). Planning and reflection should enhance the accessibility of human capital resources because these regulatory 
processes augment team members' understanding and recognition of the value of these inputs for goal-directed efforts (Frese \& Zapf, 1996; Raabe, Frese, \& Beehr, 2007; see also, Fisher, 2014; Villado \& Arthur, 2013). With regard to planning, people can plan desired actions in advance (i.e., what, when, where, and how to perform a behaviour) and anticipate likely obstacles and their potential solutions (Sniehotta, Schwarzer, Scholz, \& Schüz, 2005; Thürmer, Wieber, \& Gollwitzer, 2017). In so doing, action plans foster contingencies between contextual cues and behavioural processes that maximise efficiency towards achieving valued objectives, whereas coping plans provide mental links between anticipated risks and responses that protect and augment action plans (Sniehotta, 2009). Within the context of team resilience, the primary focus is to plan in advance for likely adverse events and identify possible courses of action that utilise the human capital resources of individuals for the collective interest of the team's objectives. Of central importance to planning in this regard is the expectation of known or predictable variables, such as the nature of the adversity and its potential effects on individual inputs and team processes. The formation of action and coping plans is a conscious or explicit act that requires cognitive processing and deliberation, yet the mechanisms by which such plans influence behaviour are often unconscious or automatic because of heightened cue accessibility (Hagger \& Chatzisarantis, 2014; Webb \& Sheeran, 2008). As such, we expect that proactive planning efforts will enhance the likelihood that individual members access those human capital resources most instrumental to the task at hand in response to an adversity and efficiently deploy those resources most salient to the triggering event.

It is likely that some adverse events may be unanticipated during planning efforts (e.g., sudden tyre blowout on a vehicle during convoy mission through enemy territory). Experiences with both anticipated and unanticipated adverse events represent opportunities for learning and the development of positive adaptations for individuals and their contributions to the team. As such, systematic reflection plays an important role for the enhancement and refinement of team resilience (also referred to as after-event or after-action reviews; Crowe, Allen, Scott, Harms, \& Yoerger, 2017; Ellis \& Davidi, 2005). Systematic reflection involves (i) learning from failures and successes 
in performance by analysing one's behaviour and generating the most plausible explanations of behavioural processes and their links to performance outcomes; (ii) exploring alternative perspectives on how things might have occurred (i.e., counterfactual thinking); and (iii) evaluating performance in terms of success or failure and the underlying causal processes associated with these outcomes (Ellis, Carette, Anseel, \& Lievens, 2014). When these performance-related experiences are stressful or encompass adverse events, systematic reflection provides performers with a process by which to enhance their understanding of specific coping strategies and how they can be utilised in new ways or for different stressors or adversities (Crane \& Boga, 2017). Ultimately, we expect that collaborative planning and reflection efforts among team members will foster shared knowledge of task work (i.e., the 'doing' part, including task-specific requirements for collective goals), teamwork (i.e., the 'how' part, including interaction requirements and individual's capabilities), and updates over time (Araújo \& Bourbousson, 2016) that will maximise awareness of relevant human capital resources and their deployment for a range of adverse events.

\section{Proposition 4}

Team resilience emerges when individuals align and coordinate their human capital resources via behavioural, cognitive and affective mechanisms during and in response to adverse events. The integration of multilevel theory (Kozlowski \& Klein, 2000) to the conceptualisation of team resilience as an emergent outcome prompts the need to delineate the processes by which complementary combinations of human capital resources of individual team members manifest as a higher-level, collective construct. In other words, the key question refers to the "process mechanisms that drive dynamic interaction and exchange and shape the nature of emergence" (Kozlowski, 2015, p. 274 [italics in original]). Interdependence, interaction, and coordination among two or more individuals working towards one or more common objectives are the defining features of teams (Kozlowski \& Ilgen, 2006). Unsurprisingly, coordination among members is considered a critical factor for team resilience (Gomes et al., 2014). 
Conceptualised as a complex dynamic system (e.g., Ramos-Villagrasa, Marques-Quinteiro, Navarro, \& Rico, 2017; Waller, Okhuysen, \& Saghafian, 2016), teamwork involves ir/regular and (non)linear interactions among team members with functional significance to the nature of the task and context, rather than the simple aggregation of individual-level characteristics and attributes. In a military context, for example, the effectiveness of a 3-person tank crew (commander, driver, gunner) during an adverse event is not simply a linear combination of their individual human capital resources; high-quality instructions combined with low-quality driving and targeting/shooting is unlikely to result in performance that is equivalent to high-quality driving together with low-quality instructions and targeting/shooting. For team resilience to emerge, therefore, individual members need to coordinate their human capital resources in ways that are functionally specific to the demands of the task and nature of the adverse event (i.e., temporal coordination of unfolding events). We propose that teams can dynamically arrange each individual's human capital resources functionally in ways that foster effective timing and execution of interdependent tasks for achieving a common goal via behavioural, cognitive and affective mechanisms (see also, Gorman, Dunbar, Grimm, \& Gipson, 2017) ${ }^{2}$. Although the salience of each type of coordination depends on the nature of the task, adversity, or the type of team (e.g., virtual), we expect the enactment of all three forms of coordination to accelerate or maximise team resilience emergence.

Behavioural coordination refers to "the degree to which the behaviours in an interaction are non-random, patterned or synchronised in both timing [and] form" (Bernieri \& Rosenthal, 1991, p. 403). Behaviour encompasses physical acts displayed by individuals that are observable and measurable (e.g., frequency, duration) and which contribute to the attainment of goal-directed tasks. Conceptualised in this way, behavioural coordination is characterised by (i) a social interaction between two or more individuals (ii) that occurs quickly and unconsciously (iii) in simultaneous

\footnotetext{
${ }^{2}$ Various terms have been used in the literature to describe behavioural, affective, or cognitive coordination, including alignment (e.g., Garrod \& Pickering, 2004), matching (e.g., Louwerse, Dale, Bard, \& Jeuniaux, 2012), mimicry (e.g., Cheung, Slotter, \& Gardner, 2015), and synchrony (e.g., Endedijk et al., 2015). We prefer the use of coordination for consistency with the existing body of work with team units that captures the "dynamic arranging of parts to achieve a larger task or function" (Gorman, 2014, p. 355).
} 
face-to-face settings (Bernieri \& Rosenthal, 1991; Davis, 2016; Miles, Griffiths, Richardson, \& Macrae, 2010). Ample evidence exists to support the adaptiveness of functional patterns of behavioural coordination among team members within goal-directed interactions on a range of tasks including tower-building (Abney, Paxton, Dale, \& Kello, 2015), LEGO ${ }^{\circledR}$ building (Fusaroli, Bjørndahl, Roepstorff, \& Tylén, 2016), idea generation (Won, Bailenson, Stathatos, \& Dai, 2014), shepherding (Nalepka, Kallen, Chemero, Saltzman, \& Richardson, 2017), and object movement (Allsop, Vaitkus, Marie, \& Miles, 2016). The nature of the team (e.g., composition of skills) and context (e.g., task requirements) are important considerations because they affect the type of behavioural coordination (e.g., Richardson et al., 2015; Wallot, Mitkidis, McGraw, \& Roepstorff, 2016); whether it be a sequential string of actions (e.g., one soldier signals a teammate, who then enters a room) or the temporal execution of actions in unison (e.g., rowers sculling their oars). Despite these nuances, common to all examples of team activities is the need to coordinate individual members' behavioural tasks in ways that foster collective performance.

Affective coordination involves emotional states (i.e., feelings, expressions, physiological) that vary in valence (positive or negative) and arousal (low or high; Barrett, 2006). Emotions provide a wealth of information for people - via face-to-face interactions or technological mechanisms (e.g., text-based messages; e.g., Salminen, Ravaja, Kallinen, \& Saari, 2013) - such that they characterise the affective meaning of the situation (Van Kleef, 2016). Most pertinent to team resilience emergence, emotional cues represent a source of clarity during ambiguous situations (Butler, 2015; Van Kleef, Van Doorn, Heerdink, \& Koning, 2011). Subjective experiences of social-contextual emotional cues can occur via affective reactions (e.g., transmission of anxiety from one person to another) and inferential processes (e.g., cues alter one's emotional interpretation of what is happening; Parkinson \& Simons, 2009; Van Kleef, 2009). Psychophysiological indices also provide proxies into affective states of individuals (Cacioppo, Tassinary, \& Berntson, 2000). With regard to interpersonal contexts, the (co)variation among two or more individuals' physiological dynamics over time provides important information regarding social interactions and 
the shared emotional space within these settings (Palumbo et al., 2017). During periods of duress shared among team members, for example, there may be a mutual increase in heart rate across these individuals. Shared affective coordination, as indicated via synchronous heart rate dynamics for example, is associated with better team performance (e.g., faster execution with fewer errors) in task-oriented collaborative contexts (Henning, Armstead, \& Ferris, 2009; Henning, Boucsein, \& Gil, 2001), including in response to a disruptive event (Henning \& Korbelak, 2005). Presumably, affective coordination is a marker of trust between members (Mitkidis, McGraw, Roepstorff, \& Wallot, 2015). As such, the coordination of interpersonal emotional states among team members may occur in synchrony (i.e., ebbs and flows that occur in unison across members), by transmission or influence (i.e., affective reactions or inferential processes), or in terms of their coregulation (i.e., mutually converging towards or away from some type of stable state; Butler, 2015).

Cognitive coordination concerns the discretionary communication of cognitions (e.g., ideas, opinions) from one team member to another (or others) in ways that can be heard, understood, and quantified by an observer (e.g., content, duration). Cognitive coordination can occur in the presence of two or more individuals within the same physical setting and in situations when team members are dispersed by distance or geographical location (e.g., aircraft pilot being directed by a soldier on the ground during an air support mission) via technological mechanisms (e.g., radio communication). Of particular importance for team resilience emergence are the distinctions between knowledge sharing (i.e., providing task information and "know how" to assist a teammate), transfer (i.e., acquiring and applying information by the recipient), and exchange (i.e., providing information to and searching for knowledge from others; Wang \& Noe, 2010). Take the case in which an individual member experiences equipment malfunction unexpectedly; if this change in circumstance is not communicated quickly or clearly to teammates who rely on that information for them to perform their duties effectively (i.e., knowledge sharing), the effect on collective performance could be catastrophic or economically costly. Alternatively, the same negative outcomes could occur if the knowledge of equipment malfunction is shared effectively, yet the 
recipient of that information applies it ineffectively (i.e., knowledge transfer). Meta-analytic data supports the importance of information exchange for team performance (Mesmer-Magnus \& DeChurch, 2009; Mesmer-Magnus, DeChurch, Jimenez-Rodriguez, Wildman, \& Shuffler, 2011; see also, Fusaroli \& Tylén, 2016). Recent meta-analytic work has disentangled the nature of this effect, showing that communication quality (i.e., effectiveness, clarity) is more strongly related to performance than communication frequency (i.e., volume of information), most likely because communication quality fosters sharing and receiving of salient information while minimising message confusion (Marlow, Lacerenza, Paoletti, Burke, \& Salas, 2018).

For team resilience emergence, it is also important to acknowledge the distinction between explicit and implicit forms of coordination among team members (Rico et al., 2008). Consider the case of acute care teams where individuals with specialised roles are assembled for brief performances in high-risk, healthcare scenarios (e.g., emergency medicine, surgery). For these action teams, coordination among members can involve verbal communication via explicit (e.g., offering directives, asking procedural questions) or implicit mechanisms (e.g., providing taskrelevant assistance without being requested to do so), as well as behavioural actions that are explicit (e.g., assisting a team member upon request) or implicit (e.g., observing a teammates' efforts, tracking environmental conditions) in nature (Kolbe, Burtscher, \& Manser, 2013). Within the context of our model of team resilience, the foundations of explicit coordination lie in the planning and systematic reflection efforts of teams, which in turn set the stage for the development and refinement of implicit coordination through simulation and real-world experiences (Zajac et al., 2014). Both explicit and implicit forms of coordination are critical for team functioning within the context of complex working environments, particularly given the heterogeneous nature of adversity (Williams, Gruber, Sutcliffe, Shepherd, \& Zhao, in press). Nevertheless, implicit coordination among team members is particularly important during unanticipated events, crises, and highpressure situations (Espinosa, Lerch, \& Kraut, 2004). The existence of high-quality shared mental models among members renders external sources of information less important for collective 
behaviour during dynamic interactions because the team has at its disposal organised repertoires of salient activities and behaviours including their temporal dimensions that are shared among individuals (Cannon-Bowers, Salas, \& Converse, 1993; Ellis, 2006; Mohammed, Hamilton, Tesler, Mancuso, \& McNeese, 2015). As such, team resilience emerges via a combination of explicit and implicit coordination processes (see also Rico et al., 2008). With rapid and ongoing advances in technology, researchers have at their disposal a broad range of methods to assess coordination objectively, including video analysis, motion tracking, and psychophysiological and neurophysiological techniques (for reviews, see Cornejo, Cuadros, Morales, \& Paredes, 2017; Thorson, West, \& Mendes, in press).

\section{Proposition 5}

\section{The effects of human capital resources on team coordination efforts are transmitted}

via group norms. Given the centrality of social dynamics to team resilience emergence, it is important to consider factors that enable teams to capitalise on potential synergies and therefore coordinate their human capital resources via behavioural, cognitive and affective mechanisms. We propose that group norms are a key mechanism through which human capital resources translate into behavioural, cognitive and affective coordination for team resilience emergence. From a social identity perspective, norms reflect cognitive representations of shared patterns of thoughts, feelings, and behaviours that characterise regularities among a group and differentiate it from others (Haslam, Turner, Oakes, McGarty, \& Reynolds, 1997; Hogg \& Reid, 2006). Information contained within norms describe how group members should think, act, and feel in a given context. Group members will then strive to behave in ways that are consistent with the norms of their group (Terry \& Hogg, 1996; Turner et al., 1987). In this way, norms are a crucial determinant of how and which individual resources are coordinated at the team-level. Group norms and social influence are intertwined, and it is through norm generation that team memberships allow the coordination of group-based behaviour (Turner et al., 1987). Normative information that governs the coordination of team behaviour vary in their content. For example, norms may emphasise cooperation among 
team members (i.e., emphasis on shared pursuits, shared objectives and interests; Chatman \& Flynn, 2001) and define the goals and role of the group in the context of a larger organisation (e.g., accounts management team). Norms are salient for team resilience (Edson, 2012; Morgan et al., 2013) because they afford unique and important information to guide members about how to approach and respond to adverse events experienced by the team. Importantly, different norms result in different behavioural outcomes (Jetten, Spears, \& Manstead, 1996), with some norms resulting in adaptive outcomes, and therefore maximising team resilience emergence, whereas others might be effecting maladaptive outcomes and thus thwarting team resilience emergence.

Human capital resources of individual members play an important role in determining the nature of norms within a team. With regard to surface-level characteristics, heterogeneity of team demographics is related to low degrees of cooperative norms during the early emergence of a group (Chatman \& Flynn, 2001). Similar findings have been observed with regard to deep-level characteristics; for example, team-level mean (additive) and variance (dispersion) scores of extraversion and mean scores of agreeableness are positively associated with cooperative group norms, whereas variance on agreeableness are inversely related with team norms (Gonzalez-Mulé, DeGeest, McCormick, Seong, \& Brown, 2014). The skills, knowledge, and expectations of team members provide information about what teams do, how they are defined, and what function they perform within the broader context of the organisation. For example, team member expectations for collaborative problem solving are associated with the formation of team problem solving norms (Taggar \& Ellis, 2007). Thus, individual-level human capital resources are fundamental inputs to the content of norms, such that their composition within a team influences the degree to which cooperative group norms are developed and sustained. In turn, group norms transmit the effects of human capital resources into coordination efforts because they maximise cooperation, integration, and interdependence among members and, therefore, the optimisation of resource compositions for collective energy and interdependent goal progress (O'Reilly \& Chatman, 1996).

\section{Proposition 6}




\section{Leaders shape (a) the formation of group norms and, in turn, (b) bolster coordination}

efforts among team members. The importance of leaders and leadership behaviour for team resilience is well documented (e.g., Alliger et al., 2015; Gomes et al., 2014; Morgan et al., 2013). Meta-analytic data indicates that leadership behaviour positively affects team effectiveness (Wang, Waldman, \& Zhang, 2014) and performance outcomes (Burke et al., 2006; D’Innocenzo, Mathieu, \& Kukenberger, 2016). As leader expectations and leadership style are related to the formation of team norms (Ishikawa, 2012; Tagger \& Ellis, 2007), we predict leaders to play an important role in informing the content of norms that guide coordination. Within the context of team resilience emergence, leaders foster coordination and integration of team members' interdependent work because of their primary responsibility for defining team objectives, and the ways by which the team organises and works to accomplish those goals (e.g., procedures, rules, plans; Klein, Ziegert, Knight, \& Xiao, 2006; Okhuysen \& Bechky, 2009). In this way, leaders provide information regarding team goals, how these goals are accomplished via explicit direction or modelling, and often a combination of both. Leadership within military settings, for example, requires shifts in leader behaviours and styles relative to contextual demands, including (i) functional and problemsolving approaches (e.g., identify and communicate solutions, implementation of plans); (ii) dyadic forms that encompass investments from the leader (e.g., support another's self-worth) and returns from the follower or peer (e.g., deliver competent performance); and (iii) collective methods in which leadership is distributed among members who possess pertinent knowledge, skills or abilities for specific contextual demands (Yammarino, Mumford, Connelly, \& Dionne, 2010). Leadership style and associated behaviours inform normative information in ways that maximise team-level coordination and therefore team resilience emergence.

\section{Proposition 7}

\section{Team identification moderates the effects of group norms on coordination efforts.}

Identification with the team is important when determining the capacity of norms to influence behaviour, such that we expect team identification to moderate the effect of norms on coordination. 
Identification with a social entity refers to the internalisation of one's membership of a team or other social group as part of their self-concept ("we" and "us" versus "I" and "me"; Tajfel \& Turner, 1979). Formally, social identities have been defined as aspects of self-concept that are based on group memberships and associated behavioural and psychological content (Tajfel \& Turner, 1979; Turner, Oakes, Haslam, \& McGarty, 1994). Categorisation of the self as a team member is considered to serve as the basis on which behavioural uniformity operates. From a social identity perspective (Turner, et al., 1987, 1994), the perception of the self as a group member, rather than as a unique individual, is a necessary precondition for group-based behavioural coordination. The identification of the self as a group member is also likely to influence the enactment of, or adherence to team norms particularly relevant during stressful experiences, because norms provide a common interpretative framework for stress appraisals. For example, norms may increase the likelihood of social support because members share a social identity, and maximise the effectiveness of received support through minimisation of misinterpretation of intent (Haslam, Jetten, Postmes, \& Haslam, 2009; see also, Gallagher, Meaney, \& Muldoon, 2014; Haslam, Jetten, O’Brien, \& Jacobs, 2004; Ketturat et al., 2016). Thus, group norms are expected to be most influential for cognitive, affective, and behavioural coordination efforts when there is a psychological merger of the self and team among members.

\section{Proposition 8}

\section{Shared mental models moderate the effects of human capital resources on coordination}

efforts. Planning and systematic reflection set the stage for both explicit and implicit forms of situation awareness (e.g., Fung et al., 2015; Riley, Endsley, Bolstad, \& Cuevasm, 2006), and therefore the transition from inputs to processes of team resilience emergence. Of particular relevance in this regard are individuals' psychological representations of the environment that are characterised by descriptions, observations, and explanations of situational details and which serve to foster coherence and meaningfulness in the storage and access of knowledge for enacting goaldirected behaviour (Rouse \& Morris, 1986). These personal reference frameworks, or mental 
models, are adjusted continuously over time as individuals accrue experience with the occupational context and team members through dynamic interactions in the work environment (e.g., working in same context, sharing responsibilities; Zajac, Bedwell, Kramer, \& Salas, 2014). As mental models are based on information and knowledge, collaborative planning and reflection provides individuals with an amplified pool of perspectives regarding the salient features of the team's objectives to help them refine their psychological representations of the environment. In turn, these team learning processes have the potential to foster a common "road map" or a shared understanding of task (e.g., objectives, available resources) and teamwork (e.g., interpersonal interactions, teammates' skills) knowledge that provides the basis to understand and anticipate their team members' behaviours (Cannon-Bowers et al., 1993; Mathieu, Heffner, Goodwin, Salas, \& Cannon-Bowers, 2000).

Shared team mental models underpin compatible interpretations of changes in the work environment (Cannon-Bowers et al., 1993), anticipation of the needs and actions of members during challenging times (DeChurch \& Mesmer-Magnus, 2010; Rico, Sánchez-Manzanares, Gil, \& Gibson, 2008), and efficient and effective coordination among team members (Mohammed \& Dumville, 2001). For these reasons, shared mental models are essential for high performance among teams (DeChurch \& Mesmer-Magnus, 2010). Most important for team resilience emergence is planning for expected adverse events and systematic reflections of experienced adversities for the creation and refinement of individual and shared mental models regarding the salience of human capital resources and their effective deployment. The presence of shared and adaptive mental models is expected to enhance the likelihood of behavioural, cognitive and affective coordination between members in response to adverse events.

\section{Proposition 9}

The accumulation of collective experiences in dealing with adversity enables teams to develop a shared perception of the team regarding their capability to resist, bounce back, and recover from adverse events. We expect that over time - as teams accrue collaborative experiences in dealing with adverse events - team resilience emergence also involves composition 
in that individuals develop a shared perception of the team that is characterised by an assessment of their collective capabilities to withstand, bounce back, and recover from future adverse events. This conceptualisation of team resilience shares similarities with collective efficacy in that it represents a group's "shared belief in its conjoint capabilities to organise and execute the courses of action required to produce given levels of attainments" (Bandura, 1997, p. 477). Yet we propose that this aspect of team resilience emergence is best conceptualised as a specific type of group-level efficacy that it is rooted in shared beliefs around what a team can accomplish in response to adverse events; in contrast, collective efficacy is typically pertinent for those situations that do not encompass 'out of the ordinary' circumstances (see Table 3). This conceptual distinction is subtle yet fundamentally important for operationalisation (e.g., "My team has the necessary capabilities to perform well" versus "My team is capable of withstanding the potential maladaptive effects of major stressors or adversities on team functioning") and the potential utility of evidence generated because contextually tailored operationalisations of efficacy are often better predictors than global or generalised assessments (Bandura, 2006; Stajkovic, Lee, \& Nyberg,. 2009).

Unlike compilation constructs, which reflect the pattern or configuration of lower-level characteristics or their interaction, composition constructs converge or coalesce over time to capture characteristics that are common or shared among lower-level inputs (i.e., individual members of the team; Kozlowski \& Klein, 2000). As a composition construct, this shared perception takes some time to emerge as teams mature as a collective entity via social interactions and mutual task experiences (Kozlowski, 2012). Of central importance here is the experience of adverse events that threaten the functioning of the team when working towards objectives that are shared and valued. Within the context of our conceptual model, therefore, adversity serves to activate individual- (i.e., human capital resources) and team-level (i.e., leadership, norms, mental models) inputs into the emergence process, and a shared belief among team members regarding their collective capacity to manage such threats to their functioning. As with beliefs regarding oneself (Bandura, 1997), we expect mastery experiences (e.g., collective experiences in successfully resisting, bouncing back or 
recovering from adversity), verbal persuasion (e.g., team member's discussing past success in task planning), vicarious experiences (e.g., observing teammates perform tasks effectively in response to adversity), and physiological or affective states (e.g., arousal levels of team members) to play an important role in the development of these shared beliefs within a team.

\section{Methodological Considerations for the Science of Team Resilience Emergence}

The conceptualisation of team resilience as an emergent outcome has important implications for the operationalisation of key concepts and the interpretation of empirical findings. As such, it is important to consider methodological issues that can enable researchers to disentangle unique inputs into the system and the processes by which they translate into the emergence of team resilience. Doing so will enable researchers to maximise alignment between concept and method.

\section{Dynamic and Temporal Perspectives Matter}

With few exceptions (e.g., Gorman et al., 2016; Savioja et al., 2014), the majority of past work on team resilience has relied on cross-sectional surveys or interviews in which participants recollect and evaluate their experiences. Cross-sectional studies provide important insights into associations warranting additional investigation using methods that permit inferences into temporal dynamics or cause-and-effect pathways, yet an inherent assumption of statistic methods is that variables are stable across time and context. Perhaps most important for the science of team resilience emergence, cross-sectional designs are suboptimal because they are unable to provide insight into the dynamic features that characterise this concept. It is impossible to ascertain whether teams have resisted, bounced back, or recovered well from an adverse event without an understanding of their functioning prior to this experience. Relatedly, one cannot speak to the protectiveness or resilience-enhancing properties of human capital resources unless they have been associated with resilient outcomes relative to baseline levels of functioning. For these reasons, the use of cross-sectional snapshots of key variables represents a mismatch between method and theory on resilience (Bonanno et al., 2015; Luthar et al., 2000; Masten \& Narayan, 2012). 
To study team resilience in ways that are useful for advancing theory and practice, it is essential to define and measure four critical elements: (i) baseline or pre-adversity functioning (i.e., how well the team was doing prior to adversity), (ii) actual adverse event (i.e., the nature of the adversity in terms of timing, duration and frequency), (iii) post-adversity functioning (i.e., how well the team is doing relative to baseline or pre-adversity levels and the aversive circumstances), and (iv) determinants of functioning throughout the temporal sequence (i.e., what attributes, conditions, and processes foster or thwart the likelihood of positive outcomes; Bonanno et al., 2015; see also, Garmezy, Masten, \& Tellegen, 1984; Luthar, 1991). For these reasons, it is conceptually defensible to study empirically and theorise about team resilience only when functioning is observed after exposure to an adverse event, and is considered in relation to the functioning of the team prior to the adversity. In other words, resilience is only understood fully when dynamic person-situation interactions and their outcomes are examined over time (Bonanno, 2004; Luthar et al., 2000; Masten \& Narayan, 2012). It is therefore imperative that efforts to clarify theoretical perspectives and inform practice are underpinned by designs that permit an understanding of the temporally dynamic features of team resilience over timeframes that facilitate an understanding of the different trajectories of team performance. There is a need for future work to adopt designs that permit direct tests of these propositions in ways that foster congruence between theory, concepts, and method.

\section{Measurement of Team Resilience Emergence Matters}

Conceptualising team resilience as a higher-level construct that encompasses both compilation and composition forms of emergence has important implications for the operationalisation of team resilience in that researchers need to specify which form of emergence is the focus of an investigation. For compilation emergence, the higher-level construct is distinctively different from the lower-level construct in that performance trajectories over time are characterised by a complex combination of individual-level inputs formed via dynamic interaction processes and contextual contingencies (Kozlowski \& Klein, 2000). Specifically, unique human capital resources across team members are combined interactively or causally through sequential interdependence 
(Ployhart et al., 2014) to produce a meaningful team performance trajectory. As the defining characteristic of team resilience compilation, performance is functionally equivalent across levels, yet structurally different for individual members and the team as a collective (Kozlowski \& Chao, 2012; Kozlowski et al., 2013). In other words, individuals contribute unique performance objectives based on their role within the team that combine via dynamic interactions to generate team performance. Within the context of an emergency response team, for example, the team leader is often charged with different roles and responsibilities (e.g., manage flow of information among personnel) than first responders (e.g., gather and analyse salient contextual information regarding the emergency) and specialists (e.g., deliver domain-specific services such as safety, medical and environmental). To study team resilience as a compilation construct via observational designs, researchers require an understanding of the objective(s) of the team for a specific context to identify salient indicators of functioning within that context. Alternatively, within the context of experimental designs in the lab or field, researchers must convey to participants the team objective salient to the task. In other words, in one context the researcher seeks out this information from participants but in the other provides the team objective to them.

With regard to composition emergence, team resilience is the function of both individual level interpretations of the team's capability to resist, bounce back or recover from deteriorations in functioning following adversity, and the shared perception of these interpretations among team members. As individual level perceptions are subject to personal idiosyncrasies, the assessment of composition emergence requires a metric that integrates and summarises the temporal and contextual features of team resilience (Bliese, 2000). Team resilience is, therefore, best characterised by a referent-shift composition model in which the locus of perceptions originates at the individual level yet is aggregated to form a higher-level construct (Chan, 1998; Chen, Mathieu, \& Bliese, 2004). Team-referents (e.g., "My team bounces back from adversity") are preferred to individual-referents (e.g., "I bounce back from adversity") in such instances (Kozlowski, 2012) because they align operationalisation with the true theoretical referent as the aggregate often yields 
higher agreement (Klein et al., 2001). Examinations of within-team variance permits an estimation of the degree to which composition has occurred within a team; low variance or high agreement within a team provides evidence that the target construct is shared among individual raters (Kozlowski \& Klein, 2000). In such cases, team members' perceptions should cluster around the mean and therefore represent a meaningful representation of a higher-level construct (James, 1982). The consensus emergence model is a statistical approach developed recently to facilitate such tests of bottom-up emergent processes (see Lang \& Bliese, in press; Lang, Bliese, \& de Voogt, in press).

\section{Team Type and Context Matters}

Context is important for behaviour within occupational settings (Johns, 2006) so it is unlikely that team resilience emergence will be similar across all types of situations and for all types of teams. It is important that researchers provide specificity with regard to the types of teams employed to test these propositions because of the diversity of tasks, samples and contexts within organisational settings (Mathieu, Maynard, Rapp, \& Gilson, 2008). A dimensional scaling approach can facilitate the specification of the types of teams studied in future research via four broad yet sufficiently integrative contextual dimensions of teams (Abbey, Callow, Zu, \& Wilbon, 2015; Hollenbeck, Beersma \& Schouten, 2012). Existing factors of individuals (e.g., personality), the team (e.g., formation), and the context (e.g., work design), as well as the structural dependencies among members, shape and constrain decisions regarding who does what (skill differentiation) and who takes charge for decisions regarding team processes (authority differentiation). Structural linkages also differ in terms of the temporal stability of membership and expectations regarding teamwork, which may range from short-term connections to long-lasting engagements. The final dimension of virtuality refers to the distance or geographical dispersion between members of a team (Foster, Abbey, Callow, Zu, \& Wilbon, 2015). By identifying and testing these propositions across a broad range of teams who differ with regard to these four dimensional scaling factors, it will be possible to detect what individual human capabilities, and what types of team processes, facilitate a team's responses to adverse events and the emergence of team resilience. 


\section{Methodological Diversity Matters}

Past research on multilevel, emergent phenomena within organisational settings has relied on qualitative approaches in which emergence is inferred from participants' retrospective reports (e.g., interviews) or researchers' constructive interpretations of their immersion within the environment of the target system (e.g., ethnography; Kozlowski et al., 2013). This type of research is important as a foundation for theory development because it enables rich descriptions of system inputs, contextual factors, temporal processes, and outcomes. Yet to enhance the depth and breadth of our understanding of team resilience emergence, and maximise the translational benefits of this information for practice, it is important that researchers embrace methodological diversity and apply innovative approaches in their efforts to study this concept.

One valuable methodological direction is to test these conceptual propositions via agentbased, computational simulations, and experimentation using virtual and real-world tasks because they permit a comprehensive examination of factors and processes central to the dynamics of emergence that would be otherwise resource intensive to study using human participants (Kozlowski, Chao, Grand, Braun, \& Kuljanin, 2016). Agent-based modelling, for example, enables analysts to model features of agents (e.g., personality characteristics) and their interactions (e.g., coordination), and simulate dynamic, repeated interactions between multiple agents and their environment over time to study the theoretical mechanisms of emergence (for reviews, see Jackson, Rand, Lewis, Norton, \& Gray, 2017; Smaldino, Calanchini, \& Pickett, 2015). The nature of emergence can be investigated in agent-based models through virtual experimentation in which researchers manipulate aspects of the inputs into the system and/or the processes by which agents interact to identify intervention targets (Kozlowski et al., 2016). As an example, Grand, Braun, Kuljanin, Kozlowski, and Chao (2016) manipulated differences in agents' information processing skill, the frequency with which agents communicated with each other, and the proportion of information or knowledge that was unique versus common to agents in their virtual examination of team knowledge emergence. Given the limited theoretical and empirical work on team resilience to 
date, we believe agent-based, computational simulations, and virtual experimentation can shine a light on specific inputs and processes that have the greatest potential for success in resource intensive investigations of multilevel, dynamic constructs.

\section{Conclusions}

Conceptualised as a multilevel emergent construct, the next frontier for the science of team resilience is to incorporate process mechanisms inherent within dynamic interactions among individual members of a team over time and in the context of task demands, objectives and adverse events. Our conceptual model departs from and extends existing conceptual and empirical work because it clarifies and distinguishes the inputs (human capital resources, leadership, norms, mental models), processes (planning, reflection, and coordination), and outcomes (trajectories of functioning and a shared belief) of team resilience emergence within a unifying framework. We highlighted these conceptual details of team resilience emergence via nine key propositions: (i) an optimal mix of members in terms of human capital resources sets the stage for team resilience; (ii) adversity sets off in motion team resilience emergence because (iii) such situations require that teams access and deploy salient human capital resources to minimise the potentially deleterious effects of the contextual demands; (iv) the deployment of complementary combinations of human capital resources catalyses behavioural, affective, and cognitive coordination efforts among team members; (v) the effects of human capital resources on coordinated efforts are transmitted via group norms; (vi) leaders determine the content and salience of group norms which in turn maximise team coordination; (vii) the influence of group norms on coordination efforts is altered by identification with the team; (viii) the effects of human capital resources on team coordination is moderated by mental models; and (x) as dynamic entities, teams who accumulate collective experiences in dealing with adversity develop a shared perception of their team regarding their capability to resist, bounce back or recover from adverse events. Conceptualised in this way, we believe our conceptual model provides an important blueprint for shaping future work on team resilience including guiding the development of testable hypotheses. 


\section{References}

Abney, D. H., Paxton, A., Dale, R., \& Kello, C. T. (2015). Movement dynamics reflect a functional role for weak coupling and role structure in dyadic problem solving. Cognitive Processing, 16, 325-332. doi: 10.1007/s10339-015-0648-2

Adegbesan, J. A. (2009). On the origins of competitive advantage: Strategic factor markets and heterogeneous resource complementarity. Academy of Management Review, 34, 463-475. doi: 10.5465/AMR.2009.40632465

Alliger, G. M., Cerasoli, C. P., Tannenbaum, S. I., \& Vessey, W. B. (2015). Team resilience. Organisational Dynamics, 3, 176-184. doi: 10.1016/j.orgdyn.2015.05.003

Allsop, J. S., Vaitkus, T., Marie, D., \& Miles, L. K. (2016). Coordination and collective performance: Cooperative goals boost interpersonal synchrony and task outcomes. Frontiers in Psychology, 7: 1462. doi: 10.3389/fpsyg.2016.01462

American Psychiatric Association. (2013). Diagnostic and statistical manual of mental disorders (5th ed.). Washington: Author.

Araújo, D., \& Bourbousson, J. (2017). Theoretical perspectives on interpersonal coordination for team behaviour. In P. Passos, K. Davids, \& J. Y. Chow (Eds.), Interpersonal coordination and performance in social systems (pp. 126-139). New York, NY: Routledge.

Bandura, A. (1997). Self-efficacy: The exercise of control. New York: W. H. Freeman.

Bandura, A. (2006). Guide for constructing self-efficacy scales. In F. Pajares \& T. Urdan (Eds.), Self-efficacy beliefs of adolescents (pp. 307-337). Greenwich, CT: Information Age Publishing.

Barney, J. (2001). Is the resource-based "view" a useful perspective for strategic management research? Yes. Academy of Management Review, 26, 41-56. doi: 10.5465/AMR.2001.4011928

Barrett L. F. (2006). Are emotions natural kinds? Perspectives on Psychological Science, 1, 28-58. doi: 10.1111/j.1745-6916.2006.00003.x

Becvar, D. S. (Ed.) (2013). Handbook of family resilience. New York, NY: Springer. 
Bernieri, F. J., \& Rosenthal, R. (1991). Interpersonal coordination: behavioural matching and interactional synchrony. In R. S. Feldman \& B. Rimé (Eds.), Fundamentals of Nonverbal Behaviour (pp. 401-432). New York, NY: Cambridge University Press.

Blascovich, J., \& Tomaka, J. (1996). The biopsychosocial model of arousal regulation. In M. P. Zanna (Ed.), Advances in experimental social psychology, 28 (pp. 1-51). San Diego, CA: Academic Press.

Blatt, R. (2009). Resilience in entrepreneurial teams: Developing the capacity to pull through. Frontiers of Entrepreneurship Research, 29: article 1.

Bliese, P. D. (2000). Within-group agreement, non-independence, and reliability: Implications for data aggregation and analysis. In K. J. Klein \& S. W. J. Kozlowski (Eds.), Multilevel theory, research, and methods in organizations: Foundations, extensions, and new directions (pp. 349381). San Francisco, CA: Jossey-Bass.

Bonanno, G. A. (2004). Loss, trauma, and human resilience: Have we underestimated the human capacity to thrive after extremely aversive events? American Psychologist, 59, 20-28. doi: 10.1037/0003-066X.59.1.20

Bonanno, G. A. (2012). Uses and abuses of the resilience construct: Loss, trauma, and healthrelated adversities. Social Science and Medicine, 74, 753-756.

doi:10.1016/j.socscimed.2011.11.022

Bonanno, G. A., Romerso, S. A., \& Klein, S. I. (2015). The temporal elements of psychological resilience: An integrative framework for the study of individuals, families, and communities. Psychological Inquiry, 26, 139-169. doi: 10.1080/1047840X.2015.992677

Bonanno, G. A., Westphal, M., \& Mancini, A. D. (2011). Resilience to loss and potential trauma. Annual Review of Clinical Psychology, 7, 511-535. doi: 10.1146/annurev-clinpsy-032210104526 
Bowers, C., Kreutzer, C., Cannon-Bowers, J., \& Lamb, J. (2017). Team resilience as a second-order emergent state: A theoretical model and research directions. Frontiers in Psychology, 8: 1360. doi: 10.3389/fpsyg.2017.01360

Burke, C. S., Stagl, K. C., Klein, C., Goodwin, G. F., Salas, E., \& Halpin, S. M. (2006). What type of leadership behaviors are functional in teams? A meta-analysis. The Leadership Quarterly, 17, 288-307. doi: 10.1016/j.leaqua.2006.02.007

Busse, C., Kach, A. P., \& Wagner, S. M. (2017). Boundary conditions: What they are, how to explore them, why we need them, and when to consider them. Organisational Research Methods, 20, 574-609. doi: 10.1177/1094428116641191

Butler, E. A. (2015). Interpersonal affect dynamics: it takes two (and time) to tango. Emotion Review, 7, 336-341. doi: 1754073915590622.

Butler, L. D., Koopman, C., Azarow, J., Blasey, C. M., Magdalene, J. C., DiMiceli, S., ... Spiegel, D. (2009). Psychosocial predictors of resilience after the September 11, 2001 terrorist attacks. Journal of Nervous and Mental Disease, 197, 266-273. doi: 10.1097/NMD.0b013e31819d9334

Cacioppo, J. T., Tassinary, L. G., \& Berntson, G. G., (2000). Psychophysiological science. In J. T. Cacioppo, L. G. Tassinary, \& G. G. Berntson (Eds.), Handbook of sychophysiology (pp. 3-26). Cambridge: Cambridge University Press.

Cacioppo, J. T., Reis, H. T., \& Zautra, A. J. (2011). Social resilience: The value of social fitness with an application to the military. American Psychologist, 66, 43-51. doi: 10.1037/a0021419

Cannon-Bowers, J. A., Salas, E., \& Converse, S. (1993). Shared mental models in expert team decision making. In N. J. Castellan (Ed.), Individual and group decision making (pp. 221-246). Hillsdale, MI: Lawrence Erlbaum.

Chan, D. (1998). Functional relations among constructs in the same content domain at different levels of analysis: A typology of composition models. Journal of Applied Psychology, 83, 234246. doi: 10.1037/0021-9010.83.2.234 
Chatman, J. A., \& Flynn, F. J. (2001). The influence of demographic heterogeneity on the emergence and consequences of cooperative norms in work teams. Academy of Management Journal, 44, 956-974. doi: 10.2307/3069440

Chen, G., Mathieu, J. E., \& Bliese, P. D. (2004). A framework for conducting multi-level construct validation. In J. Yammarino \& F. Dansereau (Eds.), Research in multilevel issues: Multilevel issues in organizational behaviour and processes, vol. 3 (pp. 273-303). Oxford, UK: Elsevier.

Cheung, E. O., Slotter, E. B., \& Gardner, W. L. (2015). Are you feeling what I'm feeling? The role of facial mimicry in facilitating reconnection following social exclusion. Motivation and Emotion, 39, 613-630. doi: 10.1007/s11031-015-9479-9

Christian, J. S., Christian, M. S., Pearsall, M. J., \& Long, E. C. (2017). Team adaptation in context: An integrated conceptual model and meta-analytic review. Organisational Behaviour and Human Decision Processes, 140, 62-89. doi: 10.1016/j.obhdp.2017.01.003

Cornejo, C., Cuadros, Z., Morales, R., \& Paredes, J. (2017). Interpersonal coordination: Methods, achievements, and challenges. Frontiers in Psychology, 8:1685. doi: 10.3389/fpsyg.2017.01685

Cornelissen, J. (2017). Editor's comments: Developing propositions, a process model, or a typology? Addressing the challenges of writing theory without a boilerplate. Academy of Management Review, 42, 1-9. doi: 10.5465/amr.2016.0196

Crane, M., \& Boga, D. (2017). A commentary: Rethinking approaches to resilience and mental health training. Journal of Military \& Veterans' Health, 25, 30-33.

Croft, D. G., Banbury, S. P., Butler, L. T., \& Berry, D. C. (2004). The role of awareness in situation awareness. In S. Banbury \& S. Tremblay (Eds.), A cognitive approach to situation awareness: Theory and application (pp. 82-103). Bodmin, Cornwall: MPG Books Ltd.

Crowe, J., Allen, J. A., Scott, C.W., Harms, M., \& Yoerger, M. (2017). After-action reviews: The good behaviour, the bad behaviour, and why we should care. Safety Science, 96, 84-92. doi: 10.1016/j.ssci.2017.03.006 
Davis, T. (2016). The ties that bind: unintentional spontaneous synchrony in social interactions. In P. Passos, K. Davids, \& J. Y. Chow (Eds.), Interpersonal coordination and performance in social systems (pp. 53-64). New York, NY: Routledge.

DeChurch, L. A., \& Mesmer-Magnus, J. R. (2010). The cognitive underpinnings of effective teamwork: A meta-analysis. Journal of Applied Psychology, 95, 32-53. doi: 10.1037/a0017328

D’Innocenzo, L., Mathieu, J. E., \& Kukenberger, M. R. (2016). A meta-analysis of different forms of shared leadership-team performance relations. Journal of Management, 42, 1964-1991. doi: $10.1177 / 0149206314525205$

Duff, S., Del Guidice, K., Flint, J., Nguyen, N., \& Kudrick, B. (2014). The diagnosis and measurement of team resilience in sociotechnical systems. 7th International Symposium on Resilient Control Systems (ISRCS), pp. 1-5. doi: 10.1109/ISRCS.2014.6900088

Edson, M. C. (2012). A complex adaptive systems view of resilience in a project team. Systems Research, 29, 499-516. doi: 10.1002/sres.2153

Ellis, S., Carette, B., Anseel, F., \& Lievens, F. (2014). Systematic reflection: Implications for learning from failures and successes. Current Directions in Psychological Science, 23, 67-72. doi: $10.1177 / 0963721413504106$

Ellis, A. P. J. (2006). System breakdown: The role of mental models and transactive memory in the relationship between acute stress and team performance. Academy of Management Journal, 49, 576-589. doi: 10.5465/AMJ.2006.21794674

Ellis, S., \& Davidi, I. (2005). After event reviews: Drawing lessons from successful and failed experience. Journal of Applied Psychology, 90, 857-871. doi: 10.1037/0021-9010.90.5.857

Endedijk, H. M., Ramenzoni, V. C. O., Cox, R. F. A., Cillessen, A. H. N., Bekkering, H., \& Hunnius, S. (2015). Development of interpersonal coordination between peers during a drumming task. Developmental Psychology, 51, 714-721. doi: 10.1037/a0038980 
Endsley, M. R. (1988). Situation awareness global assessment technique (SAGAT). Proceedings of the National Aerospace and Electronics Conference (NAECON), 789-795. New York, NY: IEEE.

Endsley, M. R. (1995). Toward a theory of situation awareness in dynamic systems. Human Factors, 37, 32-64. doi: 10.1518/001872095779049543

Endsley, M. R. (1997). The role of situation awareness in naturalistic decision making. In C. E. Zsambok \& G. Klein (Eds.), Naturalistic decision making (pp. 269-283). Mahwah, NJ: Lawrence Erlbaum Associates.

Endsley, M. R. (2012). Situation awareness. In G. Salvendy (Ed.), Handbook of human factors and ergonomics (4th ed., pp. 553-568). New York, NY: Wiley.

Endsley, M. R. (2015). Situation awareness misconceptions and misunderstandings. Journal of Cognitive Engineering and Decision Making, 9, 4-32. doi: 10.1177/1555343415572631

Ennen, E., \& Richter, A. (2010). The whole is more than the sum of its parts - Or is it? A review of the empirical literature on complementarities in organisations. Journal of Management, 36, 207-233. doi: 10.1177/0149206309350083

Espinosa, J. A., Lerch, F. J., \& Kraut, R. E. (2004). Explicit versus implicit coordination mechanisms and task dependencies: One size does not fit all. In E. Salas, \& S. M. Fiore (Eds.), Team cognition: Understanding the factors that drive process and performance (pp. 107-129). Washington, DC: American Psychological Association.

Fisher, D. M. (2014). Distinguishing between taskwork and teamwork planning in teams: Relations with coordination and interpersonal processes. Journal of Applied Psychology, 99, 423-436. doi: $10.1037 / \mathrm{a} 0034625$

Fletcher, D., \& Sarkar, M. (2013). Psychological resilience: A review and critique of definitions, concepts, and theory. European Psychologist, 18, 12-23. doi: 10.1027/1016-9040/a000124 
Flint-Taylor, J., \& Cooper, C. L. (2017). Team resilience: Shaping up the challenges ahead. In M.

Crane (Ed.), Manage for resilience: A practical guide for employee well-being and organizational performance (pp. 129-149). New York, NY: Routledge.

Foster, M. K., Abbey, A., Callow, M. A., Zu, X., \& Wilbon, A. D. (2015). Rethinking virtuality and its impact on teams. Small Group Research, 46, 267-299. doi: 10.1177/1046496415573795

Frese, M., \& Zapf, D. (1996). Action as the core of work psychology: A German approach. In H. C. Triandis, M. D. Dunnette, \& J. M. Hough (Eds.), Handbook of industrial and organisational psychology (Vol. 4, pp. 271-340). Palo Alto, CA: Consulting Psychologists Press.

Fulmer, C. A., \& Ostroff, C. (2016). Convergence and emergence in organizations: An integrative framework and review. Journal of Organizational Behaviour, 37(S1), S122-S145. doi: 10.1002/job.1987

Fung, L., Boet, S., Bould, M., Qosa, H., Perrier, L., Tricco, A. . . Reeves, S. (2015). Impact of crisis resource management simulation-based training for interprofessional and interdisciplinary teams: A systematic review. Journal of Interprofessional Care, 29, 433-444. doi: $10.3109 / 13561820.2015 .1017555$

Fusaroli, R., Bjørndahl, J. S., Roepstorff, A., \& Tylén, K. (2016). A heart for interaction: Shared physiological dynamics and behavioural coordination in a collective, creative construction task. Journal of Experimental Psychology: Human Perception and Performance, 42, 1297-1310. doi: $10.1037 / \mathrm{xhp} 0000207$

Fusaroli, R., \& Tylén, K. (2016). Investigating conversational dynamics: Interactive alignment, interpersonal synergy, and collective task performance. Cognitive Science, 40, 145-171. doi: $10.1111 / \operatorname{cogs} .12251$

Gallagher, S., Meaney, S., \& Muldoon, O. T. (2014). Social identity influences stress appraisals and cardiovascular reactions to acute stress exposure. British Journal of Health Psychology, 19, 566-579. doi: 10.1111/bjhp.12056 
Garmezy, N., Masten, A. S., \& Tellegen, A. (1984). The study of stress and competence in children: A building block for developmental psychopathology. Child Development, 55, 97-111. doi: $10.2307 / 1129837$

Garrod, S., \& Pickering, M. J. (2004). Why is conversation so easy? Trends in Cognitive Science, 8, 8-11. doi: 10.1016/j.tics.2003.10.016

Gest, S. D., Reed, M., \& Masten, A. S. (1999). Measuring developmental changes in exposure to adversity: A life chart and rating scale approach. Development and Psychopathology, 11, 171192. doi: $10.1017 / \mathrm{S} 095457949900200 \mathrm{X}$

Giere, R. N. (2004). How models are used to represent reality. Philosophy of Science, 71, 742-752. doi: $10.1086 / 425063$

Goldstein, S., \& Brooks, R. E. (Eds.) (2013). Handbook of resilience in children (2 ${ }^{\text {nd }}$ ed.). New York, NY: Springer.

Gomes, J. O., Borges, M. R., Huber, G. J., \& Carvalho, P. V. R. (2014). Analysis of the resilience of team performance during a nuclear emergency response exercise. Applied Ergonomics, 45, 780-788. doi: 10.1016/j.apergo.2013.10.009

Gonzalez-Mulé, E., DeGeest, D. S., McCormick, B. W., Seong, J. Y., \& Brown, K. G. (2014). Can we get some cooperation around here? The mediating role of group norms on the relationship between team personality and individual helping behaviours. Journal of Applied Psychology, 99, 988-999. doi: 10.1037/a0037278

Gorman, J. C. (2014). Team coordination and dynamics: Two central issues. Current Directions in Psychological Science, 23, 355-360. doi: 10.1177/0963721414545215

Gorman, J. C., Dunbar, T. A., Grimm, D., \& Gipson, C. L. (2017). Understanding and modelling teams as dynamical systems. Frontiers in Psychology, 8:1053. doi: 10.3389/fpsyg.2017.01053

Gorman, J. C., Martin, M. J., Dunbar, T. A., Stevens, R. H., Galloway, T. L., Amazeen, P. G., \& Likens, A. D. (2016). Cross-level effects between neurophysiology and communication during team training. Human Factors, 58, 181-199. doi: 10.1177/0018720815602575 
Grand, J. A., Braun, M. T., Kuljanin, G., Kozlowski, S. W., \& Chao, G. T. (2016). The dynamics of team cognition: A process-oriented theory of knowledge emergence in teams. Journal of Applied Psychology, 101, 1353-1385. doi: 10.1037/ap10000136

Gully, S. M. (2000). Work teams research: Recent findings and future trends. In M. M. Beyerlein (Ed.), Work teams: Past, present and future (pp. 25-44). Amsterdam: Kluwer.

Hackman, J. R. (1987). The design of work teams. In J. Lorsch (Ed.), Handbook of organisational behaviour (pp. 315-342). Englewood Cliffs, NJ: Prentice Hall.

Hagger, M. S., \& Chatzisarantis, N. L. D. (2014). An integrated behaviour change model for physical activity. Exercise and Sport Sciences Reviews, 42, 62-69. doi:

\subsection{9/JES.0000000000000008}

Haslam, S. A., Jetten, J., O’Brien, A., \& Jacobs, E. (2004). Social identity, social influence, and reactions to potentially stressful tasks: Support for the self-categorization model of stress. Stress and Health, 20, 3-9. doi: 10.1002/smi.995

Haslam, S. A., Jetten, J., Postmes, T., \& Haslam, C. (2009). Social identity, health and well-being: An emerging agenda for applied psychology. Applied Psychology: An International Review, 58, 1-23. doi: 10.1111/j.1464-0597.2008.00379.x

Haslam, S. A., Turner, J. C., Oakes, P. J., McGarty, C., \& Reynolds, K. J. (1997). The group as a basis for emergent stereotype consensus. European Review of Social Psychology, 8, 203-239. doi: $10.1080 / 14792779643000128$

Henning, R. A., Armstead, A. G., \& Ferris, J. K. (2009). Social psychophysiological compliance in a four-person research team. Applied Ergonomics, 40, 1004-1010. doi: 10.1016/j.apergo.2009.04.009

Henning, R. A., Boucsein, W., \& Gil, M. C. (2001). Social-physiological compliance as a determinant of team performance. International Journal of Psychophysiology, 40, 221-232. doi: 10.1016/S0167-8760(00)00190-2 
Henning, R. A., \& Korbelak, K. T. (2005). Social-psychophysiological compliance as a predictor of future team performance. Psychologia, 48, 84-92. doi: 10.2117/psysoc.2005.84

Higgins, E. T., \& Brendl, C. M. (1995). Accessibility and applicability: Some "activation rules" influencing judgment. Journal of Experimental Social Psychology, 31, 218-243. doi: 10.1006/jesp.1995.1011

Hogg, M. A., \& Reid, S. A. (2006). Social identity, self-categorization, and the communication of group norms. Communication Theory, 16, 7-30. doi: 10.1111/j.1468-2885.2006.00003.x

Hollenbeck, J. R., Beersma, B., \& Schouten, M. E. (2012). Beyond team types and taxonomies: A dimensional scaling conceptualization for team description. Academy of Management Review, 37, 82-106. doi: 10.5465/armr.2010.0181

Ilgen, D. R., Hollenbeck, J. R., Johnson, M., \& Jundt, D. (2005). Teams in organizations: From Input-Process-Output models to IMOI models. Annual Review of Psychology, 56, 517-543. doi: 10.1146/annurev.psych.56.091103.070250

Ishikawa, J. (2012). Transformational leadership and gatekeeping leadership: The roles of norm for maintaining consensus and shared leadership in team performance. Asia Pacific Journal of Management, 29, 265-283. doi: 10.1007/s10490-012-9282-z

Jackson, J. C., Rand, D. G., Lewis, K., Norton, M. I., \& Gray, K. (2017). Agent based modelling: A guide for social psychologists. Social Psychological and Personality Science, 8, 387-395. doi: $10.1177 / 1948550617691100$

James, L. R. (1982). Aggregation bias in estimates of perceptual agreement. Journal of Applied Psychology, 67, 219-229. doi: 10.1037/0021-9010.67.2.219

Jamieson, J. P., Mendes, W. B., Blackstock, E., \& Schmader, T. (2010). Turning the knots in your stomach into bows: Reappraising arousal improves performance on the GRE. Journal of Experimental Social Psychology, 46, 208-212. doi:10.1016/j.jesp.2009.08.015 
Jamieson, J. P., Mendes, W. B., \& Nock, M. K. (2013). Improving acute stress responses: The power of reappraisal. Current Directions in Psychological Science, 22, 51-56. doi:10.1177/0963721412461500

Jetten, J., Spears, R., \& Manstead, A. S. (1996). Intergroup norms and intergroup discrimination: Distinctive self-categorization and social identity effects. Journal of Personality and Social Psychology, 71, 1222. doi: 10.1037/0022-3514.71.6.1222

Johns, G. (2006). The essential impact of context on organisational behaviour. Academy of Management Review, 31, 386-408. doi: 10.5465/AMR.2006.20208687

Kennedy, D. M., Landon, L. B., \& Maynard, M. T. (2016). Extending the conversation: Employee resilience at the team level. Industrial and Organisational Psychology, 9, 466-475. doi: 10.1017/iop.2016.41

Ketturat C., Frisch J. U., Ullrich J., Häusser J. A., van Dick R., \& Mojzisch A. (2016). Disaggregating within-and between-person effects of social identification on subjective and endocrinological stress reactions in a real-life stress situation. Personality and Social Psychology Bulletin, 42, 147-160. doi: 10.1177/0146167215616804

Klein, K. J., Conn, A. B., Smith, D. B., \& Sorra, J. S. (2001). Is everyone in agreement? An exploration of within-group agreement in employee perceptions of the work environment. Journal of Applied Psychology, 86, 3-16. doi: 10.1037/0021-9010.86.1.3

Klein, K. J., Ziegert, J. C., Knight, A. P., \& Xiao, Y. (2006). Dynamic delegation: Shared, hierarchical, and deindividualised leadership in extreme action teams. Administrative Science Quarterly, 51, 590-621. doi: 10.2189/asqu.51.4.590

Kolbe, M., Burtscher, M., \& Manser, T. (2013). Co-ACT-A framework for observing coordination behaviour in acute care teams. BMJ Quality \& Safety, 22, 596 - 605. doi: 10.1136/bmjqs-2012-001319 
Kossek, E. E., \& Perrigino, M. B. (2016). Resilience: A review using a grounded integrated occupational approach. The Academy of Management Annals, 10, 729 -797. doi: $10.1080 / 19416520.2016 .1159878$

Kozlowski, S. W. J. (2012). Groups and teams in organizations: Studying the multilevel dynamics of emergence. In A. B. Hollingshead \& M. S. Poole (Eds.), Research methods for studying groups and teams: A guide to approaches, tools, and technologies (pp. 260-283). New York, NY: Routledge.

Kozlowski, S. W. J. (2015). Advancing research on team process dynamics: Theoretical, methodological, and measurement considerations. Organisational Psychology Review, 5, 270299. doi: $10.1177 / 2041386614533586$

Kozlowski, S. W. J. (2018). Enhancing the effectiveness of work groups and teams: A reflection. Perspectives on Psychological Science, 13, 205-212. doi: 10.1177/1745691617697078

Kozlowski, S. W. J., \& Chao, G. T. (2012). The dynamics of emergence: Cognition and cohesion in work teams. Managerial and Decision Economics, 33, 335-354. doi:10.1002/mde.2552

Kozlowski, S. W. J., Chao, G. T., Grand, J. A., Braun, M. T., \& Kuljanin, G. (2013). Advancing multilevel research design: Capturing the dynamics of emergence. Organisational Research Methods, 16, 581-615. doi: 10.1177/1094428113493119

Kozlowski, S. W. J., Chao, G. T., Grand, J. A., Braun, M. T., \& Kuljanin, G. (2016). Capturing the multilevel dynamics of emergence: Computational modeling, simulation, and virtual experimentation. Organizational Psychology Review, 6, 3-33. doi: $10.1177 / 2041386614547955$

Kozlowski, S. W., \& Ilgen, D. R. (2006). Enhancing the effectiveness of work groups and teams. Psychological Science in the Public Interest, 7, 77-124. doi: 10.1111/j.15291006.2006.00030.x

Kozlowski, S. W. J., \& Klein, K. J. (2000). A multilevel approach to theory and research in organisations: Contextual, temporal, and emergent processes. In K. J. Klein \& S. W. J. 
Kozlowski (Eds.), Multilevel theory, research and methods in organizations: Foundations, extensions, and new directions (pp. 3-90). San Francisco, CA: Jossey-Bass.

Kwasnicka, D., Dombrowski, S. U., White, M., \& Sniehotta, F. F. (2015). Data-prompted interviews: Using individual ecological data to stimulate narratives and explore meanings. Health Psychology, 34, 1191-1194. doi:10.1037/hea0000234

Lang, J. W. B., \& Bliese, P. D. (in press). A temporal perspective on emergence: Using 3-level mixed effects models to track consensus emergence in groups. In S.E. Humphrey \& J. M. LeBreton (Eds.), The handbookfor multilevel theory, measurement, and analysis. Washington, DC: American Psychological Association.

Lang, J. W. B., Bliese, P. D., \& de Voogt, A. (in press). Modelling consensus emergence in groups using longitudinal multilevel models. Personnel Psychology. doi: 10.1111/peps.12260

Lange, D., \& Pfarrer, M. D. (2017). Editors' comments: Sense and structure - The core building blocks of an AMR article. Academy of Management Review, 42, 407-416. doi: 10.5465/amr.2016.0225

Layne, C. M., Warren, J. S., Watson, P. J., \& Shalev, A. Y. (2007). Risk, vulnerability, resistance, and resilience: toward an integrative conceptualization of posttraumatic adaptation. In M. Friedman, T. Keane, \& P. Resick (Eds.), Handbook of PTSD: Science and practice (pp. 497520). New York: Guilford Press.

Leppin, A. L., Bora, P. R., Tilburt, J. C., Gionfriddo, M. R., Zeballos-Palacios, C., Dulohery, M. M., ... Montori, V. M. (2014). The efficacy of resiliency training programs: A systematic review and meta-analysis of randomised controlled trials. PLOS ONE 9(10): e111420. doi:10.1371/journal.pone.0111420

Lo, J. C., Sehic, E., \& Meijer, S. A. (2014). Explicit or implicit situation awareness? Situation awareness measurements of train traffic controllers in a monitoring mode. In D. Harris (Ed.), Engineering psychology and cognitive ergonomics (pp. 511-521). Cham, Switzerland: Springer. 
Louwerse, M. M., Dale, R., Bard, E. G., \& Jeuniaux, P. (2012). Behavior matching in multimodal communication is synchronized. Cognitive Science, 36, 1404-1426. doi: 10.1111/j.15516709.2012.01269.x

Luthar, S. S. (1991). Vulnerability and resilience: A study of high-risk adolescents. Child Development, 62, 600-616. doi: 10.2307/1131134

Luthar, S. S., Cicchetti, D., \& Becker, B. (2000). The construct of resilience: A critical evaluation and guidelines for future work. Child Development, 71, 543-562. doi: 10.1111/14678624.00164

Marlow, S. L., Lacerenza, C. N., Paoletti, J., Burke, C. S., \& Salas, E. (2018). Does team communication represent a one-size-fits-all approach? A meta-analysis of team communication and performance. Organisational Behaviour and Human Decision Processes, 144, 145-170. doi: 10.1016/j.obhdp.2017.08.001

Masten, A. S. (2014). Global perspectives on resilience in children and youth. Child Development, 85, 6 - 20. doi:10.1007/s10567-013-0150-2

Masten, A. S., Hubbard, J. J., Gest, S. D., Tellegen, A., Garmezy, N., \& Ramirez, M. (1999). Competence in the context of adversity: Pathways to resilience and maladaptation from childhood to late adolescence. Development and Psychopathology, 11, 143-169. doi: $10.1017 /$ S0954579499001996

Masten, A. S., \& Narayan, A. J. (2012). Child development in the context of disaster, war, and terrorism: Pathways of risk and resilience. Annual Review of Psychology, 63, 227-257. doi: 10.1146/annurev-psych-120710-100356

Mathieu, J. E., Heffner, T. S., Goodwin, G. F., Salas, E., \& Cannon-Bowers, J. A. (2000). The influence of shared mental models on team process and performance. Journal of Applied Psychology, 85, 273-283. doi:10.1037/0021-9010.85.2.273

Mathieu, J. E., Kukenberger, M. R., \& D’Innocenzo, L. (2014). Time and teams. In A. J. Schipp \& Y. Fried (Eds.), Time and work (Vol 2, pp. 6-24). London: Taylor \& Francis. 
Mathieu, J. E., Maynard, M. T., Rapp, T., \& Gilson, L. L. (2008). Team effectiveness 1997-2007: A review of recent advancements and a glimpse into the future. Journal of Management, 34, 410-476. doi: 10.1177/0149206308316061

Mathieu, J. E., Tannenbaum, S. I., Donsbach, J. S., \& Alliger, G. M. (2014). A review and integration of team composition models moving toward a dynamic and temporal framework. Journal of Management, 40, 130-160. doi: 10.1177/0149206313503014

Maynard, M. T., Kennedy, D. M., \& Sommer, S. A. (2015). Team adaptation: A fifteen-year synthesis (1998-2013) and framework for how this literature needs to "adapt" going forward. European Journal of Work and Organizational Psychology, 24, 652-677. doi: $10.1080 / 1359432 x .2014 .1001376$

Maynard, M. T., \& Kennedy, D. M. (2016). Team adaptation and resilience: What do we know and what can be applied to long-duration isolated, confined, and extreme contexts. Houston, TX: National Aeronautics and Space Administration.

Meneghel, I., Martínez, I.M., \& Salanova, M. (2016). Job-related antecedents of team resilience and improved team performance. Personnel Review, 45, 505-522. doi: 10.1108/PR-04-2014-0094

Mesmer-Magnus, J. R., \& DeChurch, L. A. (2009). Information sharing and team performance: A meta-analysis. Journal of Applied Psychology, 94, 535-546. doi: 10.1037/a0013773

Mesmer-Magnus, J. R., DeChurch, L. A., Jimenez-Rodriguez, M., Wildman, J., \& Shuffler, M. (2011). A meta-analytic investigation of virtuality and information sharing in teams. Organisational Behaviour and Human Decision Processes, 115, 214-225. doi: 10.1016/j.obhdp.2011.03.002

Miles, L. K., Griffiths, J. L., Richardson, M. J., \& Macrae, C. N. (2010). Too late to coordinate: Contextual influences on behavioural synchrony. European Journal of Social Psychology, 40, 52-60. doi: 10.1002/ejsp.721 
Mitkidis, P., McGraw, J. J., Roepstorff, A., \& Wallot, S. (2015). Building trust: Heart rate synchrony and arousal during joint action increased by public goods game. Physiology \& Behaviour, 149, 101-106. doi: 10.1016/j.physbeh.2015.05.033

Mjelde, F. V., Smith, K., Lunde, P., \& Espevik, R. (2016). Military teams - A demand for resilience. Work, 54, 283-294. doi: 10.3233/WOR-162298

Mohammed, S., \& Dumville, B. C. (2001). Team mental models in a team knowledge framework: Expanding theory and measurement across disciplinary boundaries. Journal of Organizational Behaviour, 22, 89-106. doi:10.1002/job.86

Mohammed, S., Hamilton, K., Tesler, R., Mancuso, V., \& McNeese, M. (2015). Time for temporal team mental models: Expanding beyond "what" and "how" to incorporate "when". European Journal of Work and Organizational Psychology, 24, 693-709. doi:

10.1080/1359432X.2015.1024664

Morgan, P. B., Fletcher, D., \& Sarkar, M. (2013). Defining and characterising team resilience in elite sport. Psychology of Sport and Exercise, 14, 549-559. doi:

10.1016/j.psychsport.2013.01.004

Morgan, P. B., Fletcher, D., \& Sarkar, M. (2017). Recent developments in team resilience research in elite sport. Current Opinion in Psychology. doi: 10.1016/j.copsyc.2017.05.013

Morgeson, F. P., Mitchell, T. R., \& Liu, D. (2015). Event system theory: An event-oriented approach to the organizational sciences. The Academy of Management Review, 40, 515-537. doi: 10.5465/amr.2012.0099

Murphy, K. R. (2012). Individual differences. In N. Schmitt (Ed.), The Oxford handbook of personnel assessment and selection (pp. 31-47). Oxford, UK: Oxford University Press.

Nalepka, P., Kallen, R.W., Chemero, A., Saltzman, E., \& Richardson, M. J. (2017). Herd those sheep: Emergent multiagent coordination and behavioural-mode switching. Psychological Science, 28, 630-650. doi: 10.1177/0956797617692107 
Norris, F., Tracy, M., \& Galea, S. (2009). Looking for resilience: understanding the longitudinal trajectories of responses to stress. Social Science and Medicine, 68, 2190-2198. doi: 10.1016/j.socscimed.2009.03.043

Okhuysen, G., \& Bechky, B. A. (2009). Coordination in organisations: An integrative perspective. Annals of Academy of Management, 3, 463-502. doi: 10.1080/19416520903047533

O’Reilly, C. A., \& Chatman, J. A. (1996). Culture as social control: Corporations, cults, and commitment. Research in Organisational Behaviour, 18, 157-200.

Page, S. E. (2014). Where diversity comes from and why it matters? European Journal of Social Psychology, 44, 267-279. doi: 10.1002/ejsp.2016

Palumbo, R. V., Marraccini, M. E., Weyandt, L. L., Wilder-Smith, O., McGee, H. A., Liu, S., et al. (2017). Interpersonal autonomic physiology: A systematic review of the literature. Personality and Social Psychology Review, 21, 99-141. doi: 10.1177/1088868316628405

Pangallo, A., Zibarras, L., Lewis, R., \& Flaxman, P. (2015). Resilience through the lens of interactionism: A systematic review. Psychological Assessment, 27, 1-20. doi: $10.1037 /$ pas 0000024

Park, T.-Y., \& Shaw, J. D. (2013). Turnover rates and organisational performance: A meta-analysis. Journal of Applied Psychology, 98, 268-309. doi: 10.1037/a0030723

Parkinson, B., \& Simons, G. (2009). Affecting others: Social appraisal and emotion contagion in everyday decision making. Personality \& Social Psychology Bulletin, 35, 1071-84. doi: $10.1177 / 0146167209336611$

Pietrzak, R. H., \& Southwick, S. M. (2011). Psychological resilience in OEF-OIF Veterans: Application of a novel classification approach and examination of demographic and psychosocial correlates. Journal of Affective Disorders, 133, 560-568. doi: 10.1016/j.jad.2011.04.028 
Ployhart, R. E., Nyberg, A. J., Reilly, G., \& Maltarich, M. A. (2014). Human capital is dead; Long live human capital resources! Journal of Management, 40, 371-398. doi: $10.1177 / 0149206313512152$

Podsakoff, P. M., MacKenzie, S. B., \& Podsakoff, N. P. (2016). Recommendations for creating better concept definitions in the organizational, behavioural, and social sciences. Organizational Research Methods, 19, 159-203. doi: 10.1177/1094428115624965

Raabe, B., Frese, M., \& Beehr, T. A. (2007). Action regulation theory and career self-management. Journal of Vocational Behaviour, 70, 297-311. doi: 10.1016/ j.jvb.2006.10.005.

Ramos-Villagrasa, P. J., Marques-Quinteiro, P., Navarro, J., \& Rico, R. (2017). Teams as complex adaptive systems: Reviewing 17 years of research. Small Group Research, 49, 135-176. doi: $10.1177 / 1046496417713849$

Reich, J. W., Zautra, A. J., \& Hall, J. S. (2010). Handbook of adult resilience. New York, NY: Guilford.

Richardson, M. J., Harrison, S. J., Kallen, R. W., Walton, A., Eiler, B., \& Schmidt, R. C. (2015). Self-organized complementary coordination: Dynamics of an interpersonal collision avoidance task. Journal of Experimental Psychology: Human Perception and Performance, 41, 665-679. doi: $10.1037 / \mathrm{xhp} 0000041$

Rico, R., Sánchez-Manzanares, M., Gil, F., \& Gibson, C. (2008). Team implicit coordination processes: A team knowledge-based approach. Academy of Management Review, 33, 163-184. doi: 10.5465/AMR.2008.27751276

Riley, J. M., Endsley, M. R., Bolstad, C. A., \& Cuevas, H. M. (2006). Collaborative planning and situation awareness in Army command and control. Ergonomics, 49, 1139-1153. doi: $10.1080 / 00140130600612614$

Robertson, I. T., Cooper, C. L., Sarkar, M., \& Curran, T. (2015). Resilience training in the workplace from 2003 to 2014: A systematic review. Journal of Occupational and Organisational Psychology, 88, 533-562. doi: 10.1111/joop.12120 
Rodríguez-Sánchez, A.M., \& Perea, M.A. (2015). The secret of organization success: A revision on organizational and team resilience. International Journal of Emergency Services, 4, 27-36. doi: 10.1108/IJES-09-2014-0018

Rouse, W. B., \& Morris, N. M. (1986). On looking into the black box: Prospects and limits in the search for mental models. Psychological Bulletin, 100, 349-363. doi: 10.1037/00332909.100.3.349

Rousseau, D. M. (1985). Issues of level in organizational research: Multi-level and cross-level perspectives. Research in Organisational Behaviour, 7, 1-37.

Rutter, M. (2006). Implications of resilience concepts for scientific understanding. Annals of the New York Academy of Sciences, 1094, 1-12. doi: 10.1196/annals.1376.002

Salas, E., Prince, C., Baker, D. P., \& Shrestha, L. (1995). Situation awareness in team performance: Implications for measurement and training. Human Factors, 37, 1123-1136. doi: $10.1518 / 001872095779049525$

Salminen, M., Ravaja, N., Kallinen, K., \& Saari, T. (2013). Mediated cues of group emotion during knowledge-work tasks: effects on subjective and physiological responses. Interacting with Computers, 25, 60-73. doi: 10.1093/iwc/iws006

Savioja, P., Norros, L., Salo, L., \& Aaltonen, I. (2014). Identifying resilience in proceduralised accident management activity of NPP operating crews. Safety Science, 68, 258-274. doi:10.1093/oxfordhb/9780195399325.013.0106

Seery, M. D. (2013). The biopsychosocial model of challenge and threat: Using the heart to measure the mind. Social \& Personality Psychology Compass, 7, 637-653. doi:10.1111/ $\operatorname{spc} 3.12052$

Sharma, S., \& Sharma, S. K. (2016). Team resilience: Scale development and validation. Vision, 20, 37-53. doi: 10.1177/0972262916628952

Shepherd, D. A., \& Suddaby, R. (2017). Theory building: A review and integration. Journal of Management, 43, 59-86. doi: 10.1177/0149206316647102 
Smaldino, P.E., Calanchini, J., \& Pickett, C.L. (2015). Theory development with agent-based models. Organizational Psychology Review, 5, 300-317. doi: 10.1177/2041386614546944

Sniehotta, F. (2009). Towards a theory of intentional behaviour change: Plans, planning, and selfregulation. British Journal of Health Psychology, 14, 261-273. doi: $10.1348 / 135910708 \times 389042$

Sniehotta, F. F., Schwarzer, R., Scholz, U., \& Schüz, B. (2005). Action planning and coping planning for long-term lifestyle change: Theory and assessment. European Journal of Social Psychology, 35, 565-576. doi: 10.1002/ejsp.258

Southwick, S. M., Bonanno, G. A., Masten, A. S., Panter-Brick, C., \& Yehuda, R. (2014). Resilience definitions, theory, and challenges: Interdisciplinary perspectives. European Journal of Psychotraumatology, 5: 25338. doi: 10.3402/ejpt.v5.25338

Stajkovic, A. D., Lee, D., \& Nyberg, A. J. (2009). Collective efficacy, group potency, and group performance: Meta-analyses of their relationships, and test of a mediation model. Journal of Applied Psychology, 94, 814-828. doi: 10.1037/a0015659

Sundstrom, R., de Meuse, K. P., \& Futrell, D. (1990). Work teams: Applications and effectiveness. American Psychologist, 45, 120-133. doi: 10.1037/0003-066X.45.2.120

Taggar, S., \& Ellis, R. (2007). The role of leaders in shaping formal team norms. The Leadership Quarterly, 18, 105-120. doi: 10.1016/j.leaqua.2007.01.002

Tajfel, H., \& Turner, J. C. (1979). An integrative theory of intergroup conflict. In W. G. Austin \& S. Worchel (Eds.), The social psychology of intergroup relations (pp. 33-47). Monterey, CA: Brooks/Cole.

Terry, D. J., \& Hogg, M. A. (1996). Group norms and the attitude-behaviour relationship: A role for group identification. Personality and Social Psychology Bulletin, 22, 763-775. doi: $10.1177 / 0146167296228002$ 
Thorson, K. R., West, T. V., \& Mendes, W. B. (in press). Measuring physiological influence in dyads: A guide to designing, implementing, and analysing dyadic physiological studies. Psychological Methods. doi: 10.1037/met0000166

Thürmer, J. L., Wieber, F, \& Gollwitzer, P. M. (2017). Planning and performance in small groups: Collective implementation intentions enhance group goal striving. Frontiers in Psychology, 8: 603. doi: $10.3389 /$ fpsyg.2017.00603

Trafimow, D. (2009). The theory of reasoned action: A case study of falsification in psychology. Theory \& Psychology, 19, 501-518. doi: 10.1177/0959354309336319

Turner, J. C., Hogg, M., Oakes, P., Reicher, S., \& Wetherell, M. (1987). Rediscovering the social group: A self-categorisation theory. Oxford: Basil Blackwell.

Turner, J. C., Oakes, P. J., Haslam, S. A., \& McGarty, C. (1994). Self and collective: Cognition and social context. Personality and Social Psychology Bulletin, 20, 454-463. doi: $10.1177 / 0146167294205002$

Turner, J. R. (2016). Team cognition conflict: A conceptual review identifying cognition conflict as a new team conflict construct. Performance Improvement Quarterly, 29, 145-167. doi:10.1002/piq.2129

van der Beek, D., \& Schraagen, J. M. (2015). ADAPTER: Analysing and developing adaptability and performance in teams to enhance resilience. Reliability Engineering and System Safety, 141, 33-44. doi: 10.1016/j.ress.2015.03.019

van der Kleij, R., Molenaar, D., \& Schraagen, J. M. (2011). Making teams more resilient: Effects of shared transformational leadership training on resilience. Proceedings of the Human Factors and Ergonomics Society, 55, 2158-2162. doi: 10.1177/1071181311551450

Van Kleef, G. A. (2009). How emotions regulate social life the emotions as social information (EASI) model. Current Directions in Psychological Science, 18, 184-8. doi: 10.1111/j.14678721.2009.01633.x 
Van Kleef, G. A. (2016). The interpersonal dynamics of emotion: Toward an integrative theory of emotions as social information. Cambridge: Cambridge University Press.

Van Kleef, G. A., Van Doorn, E. A., Heerdink, M. W., \& Koning, L. F. (2011). Emotion is for influence. European Review of Social Psychology, 22, 114-163. doi: $10.1080 / 10463283.2011 .627192$

Villado, A. J., \& Arthur, W., Jr. (2013). The comparative effect of subjective and objective afteraction reviews on team performance on a complex task. Journal of Applied Psychology, 98, 514-528. doi: 10.1037/a0031510

Waller, M. J., Okhuysen, G. A., \& Saghafian, M. (2016). Conceptualising emergent states: A strategy to advance the study of group dynamics. Academy of Management Annals, 10, 561598. doi:10.1080/19416520.2016.1120958

Wallot, S., Mitkidis, P., McGraw, J. J., \& Roepstorff, A. (2016). Beyond synchrony: Joint action in a complex production task reveals beneficial effects of decreased interpersonal synchrony. PLoS ONE, 11, e0168306. doi: 10.1371/journal.pone.0168306

Wang, D., Waldman, D. A., \& Zhang, Z. (2014). A meta-analysis of shared leadership and team effectiveness. Journal of Applied Psychology, 99, 181-198. doi: 10.1037/a0034531

Wang, S., \& Noe, R. A. (2010). Knowledge sharing: A review and directions for future research. Human Resource Management Review, 20, 115-131. doi: 10.1016/j.hrmr.2009.10.001

Webb, T. L., \& Sheeran, P. (2008). Mechanisms of implementation intention effects: The role of goal intentions, self-efficacy, and accessibility of plan components. British Journal of Social Psychology, 47, 373-395. doi: 10.1348/014466607X267010

West, B. J., Patera, J. L., \& Carsten, M. K. (2009). Team level positivity: Investigating positive psychological capacities and team level outcomes. Journal of Organisational Behaviour, 30, 249-267. doi: 10.1002/job.593 
Wildman, J. L., Shuffler, M. L., Lazzara, E. H., Fiore, S. M., Burke, C. S., Salas, E., \& Garven, S., (2012). Trust development in swift starting action teams: A multilevel framework. Group \& Organization Management, 37, 137-170. doi: 10.1177/1059601111434202

Williams, T. A., Gruber, D. A., Sutcliffe, K. M., Shepherd, D. A., \& Zhao, E. Y. (in press). Organisational response to adversity: Fusing crisis management and resilience research streams. Academy of Management Annals. doi: 10.5465/annals.2015.0134

Windle, G., Bennett, K. M., \& Noyes, J. (2011). A methodological review of resilience measurement scales. Health and Quality of Life Outcomes, 9, 1-18. doi: 10.1186/1477-7525-98

Won, A. S., Bailenson, J. N., Stathatos, S. C. \& Dai, W. (2014). Automatically detected nonverbal behaviour predicts creativity in collaborating dyads. Journal of Nonverbal Behaviour, 38, 389-408. doi:10.1007/s10919-014-0186-0

Yammarino, F. J., Mumford, M. D., Connelly, M. S., \& Dionne, S. D. (2010). Leadership and team dynamics for dangerous military contexts. Military Psychology, 22, 15-41. doi: $10.1080 / 08995601003644221$

Zajac, S., Bedwell, W. L., Kramer, W. S., \& Salas, E. (2014). The cognitive underpinnings of adaptive team performance in ill-defined task situations: A closer look at team cognition. Organisational Psychology Review, 4, 49-73. doi: 10.1177/2041386613492787 


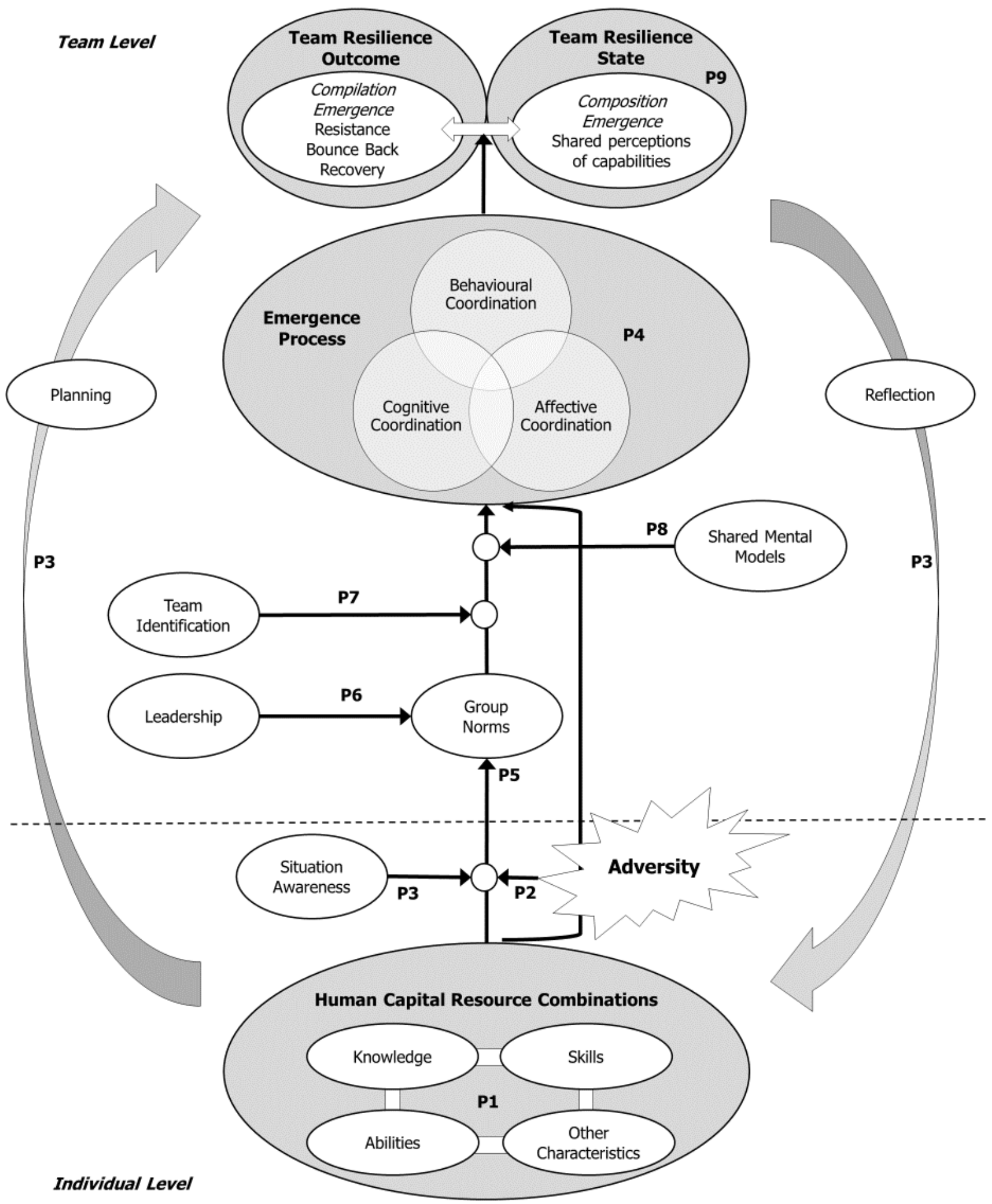

Figure 1. Multilevel model of team resilience emergence. 
Table 1

Necessary and Sufficient Conditions of Team Resilience Emergence as a Compilation Outcome (i.e., Performance Trajectory)

\begin{tabular}{|c|c|c|c|c|}
\hline Attributes & Team Resilience & Team Adaptation & $\begin{array}{l}\text { Individual } \\
\text { Resilience }\end{array}$ & Conclusion \\
\hline A1: Operates at the team level & $\checkmark$ & $\checkmark$ & $x$ & $\begin{array}{l}\text { Necessary but } \\
\text { not sufficient }\end{array}$ \\
\hline $\begin{array}{l}\text { A2: Exhibited via interactions among individual } \\
\text { members }\end{array}$ & $\checkmark$ & $\checkmark$ & $x$ & $\begin{array}{l}\text { Necessary but } \\
\text { not sufficient }\end{array}$ \\
\hline $\begin{array}{l}\text { A3: Characterised by performance indices (e.g., quality, } \\
\text { quantity) representative of collective goals or objectives }\end{array}$ & $\checkmark$ & $x$ & $x$ & $\begin{array}{l}\text { Necessary but } \\
\text { not sufficient }\end{array}$ \\
\hline A4: Triggered by an adverse event or experience & $\checkmark$ & $\checkmark$ & $\checkmark$ & $\begin{array}{l}\text { Necessary but } \\
\text { not sufficient }\end{array}$ \\
\hline $\begin{array}{l}\text { A5: Exhibited by a pattern of performance over a } \\
\text { specific temporal period }\end{array}$ & $\checkmark$ & $x$ & $\checkmark$ & $\begin{array}{c}\text { Both necessary } \\
\text { and sufficient }\end{array}$ \\
\hline A6: Team objective is organisationally relevant & $\checkmark$ & $\checkmark$ & $x$ & $\begin{array}{l}\text { Necessary but } \\
\text { not sufficient }\end{array}$ \\
\hline $\mathrm{A} 1$ and $\mathrm{A} 2$ and $\mathrm{A} 3$ and $\mathrm{A} 4$ and $\mathrm{A} 5$ and $\mathrm{A} 6$ & $\checkmark$ & $x$ & $x$ & $\begin{array}{l}\text { Necessary and } \\
\text { jointly sufficient }\end{array}$ \\
\hline
\end{tabular}




\section{Table 2}

Key Building Blocks of Four Models of Team Composition Effectiveness and their Integration (Mathieu et al., 2014)

\begin{tabular}{lcc}
\hline Number & Team Effectiveness Formula & Explanations \\
\hline & & Traditional Personnel-Position Fit Model \\
& $\mathrm{MP}_{m p}=\sum \mathrm{MC}_{m j} \mathrm{~W}_{j k} \mathrm{RI}_{k p}$ & $\mathrm{MP}_{m p}=$ performance of member $m$ in position $p$ \\
& & $\mathrm{MC}_{m j} \mathrm{w}_{j k}=$ member $m$ 's weighted competency on position task $k$, consisting of: \\
& & $\mathrm{MC}_{m j}=$ member $m$ 's score on competency $j$ \\
& & $\mathrm{w}_{j k}=$ the weight of competency $j$ in task $k$ \\
& & $\mathrm{RI}_{k p}=$ relative importance of task $k$ for performance in position $p$
\end{tabular}

Personnel Model with Teamwork Considerations

$3 \quad \mathrm{TW}_{q}=\sum\left(\mathrm{RI}_{p(m) q} \mathrm{TC}_{p(m) j}\right.$; for all $m$ and $\left.j\right)$

$\mathrm{TW}_{q}=$ Teamwork on team task $q$

$\mathrm{TC}_{(m) p j}=$ Team Competency of member $m$ in position $p$ for competency $j$

$\mathrm{RI}_{p(m) q}=$ Relative Importance of position $p$ (filled by member $m$ ) for task $q$

$4 \quad$ Team Effectiveness $=\mathrm{x} \sum \mathrm{MP}_{m p}+(1-x) \sum \mathrm{TW}_{q}$

$x=$ relative contribution of aggregate member position performances to team effectiveness

$(1-x)=$ relative contribution of teamwork to team effectiveness

\begin{tabular}{|c|c|c|}
\hline \multicolumn{3}{|r|}{ Team Profile Model } \\
\hline 5 & $\begin{array}{l}\text { Team Effectiveness }=x \sum \mathrm{MP}_{m p}+\left[(1-x) \sum \mathrm{TW}_{q}+\right. \\
\left.\left(\sum \mathrm{TPrO}_{\text {Imi }}\right)\right]\end{array}$ & $\begin{array}{l}\sum \mathrm{TPro} \mathrm{lm}=\text { sum of members } m \text { contributions to team profiles } l \\
i=\text { the relative importance of team profile } l\end{array}$ \\
\hline \multicolumn{3}{|c|}{ Relative Contribution Model } \\
\hline 6 & $\mathrm{LMP}_{m p}=\operatorname{MPm}_{p} * \sum \mathrm{MP}_{q m}{ }^{\prime}, \mathrm{I}_{q p p}$ & LMP $_{m p}=$ Linked Performance of member $m$ in position $p$ \\
\hline & & $\mathrm{MP}_{m p}=$ member $m$ 's performance on task $q$ in position $p$ \\
\hline & & $\mathrm{MP}_{q m^{\prime} p^{\prime}}^{\prime}=$ performance of member $m^{\prime}$ in position $p^{\prime}$ on task $q$, where \\
\hline & & $m^{\prime}=$ index of performance of other members in member $m$ 's team \\
\hline & & $p^{\prime}=$ other positions in member $m$ 's team \\
\hline & & $\mathrm{I}_{q p p^{\prime}}=$ The interdependence of members in positions $p$ and $p^{\prime}$ on task $q$ \\
\hline \multicolumn{3}{|c|}{ Integrative Team Contribution Model } \\
\hline 7 & $\begin{array}{l}\text { Team Effectiveness }=\mathrm{x} \sum \mathrm{LMP}_{m p}+\left[(1-x) \sum \mathrm{TW}_{q^{-}}\right. \\
\left.\left(\sum \mathrm{TPro}_{\text {lmi }}\right)\right]\end{array}$ & \\
\hline
\end{tabular}


Table 3

Necessary and Sufficient Conditions of Team Resilience Emergence as a Composition State (i.e., Shared Perception)

\begin{tabular}{lccc}
\hline \multicolumn{1}{c}{ Attributes } & Team Resilience & $\begin{array}{c}\text { Collective } \\
\text { Efficacy }\end{array}$ & Conclusion \\
\hline $\begin{array}{l}\text { A1: Evaluations of the human capital resources } \\
\text { available for collective efforts }\end{array}$ & $\checkmark$ & $\checkmark$ & $\begin{array}{c}\text { Necessary but } \\
\text { not sufficient }\end{array}$ \\
$\begin{array}{l}\text { A2: Evaluations of the team's collective ability to } \\
\text { coordinate successfully human capital resources }\end{array}$ & $\checkmark$ & $\checkmark$ & $\begin{array}{c}\text { Necessary but } \\
\text { not sufficient }\end{array}$ \\
$\begin{array}{l}\text { A3: Evaluations of the team's collective ability to } \\
\text { demonstrate desired performance trajectory following } \\
\text { adverse events }\end{array}$ & $\checkmark$ & $\begin{array}{c}\text { Necessary but } \\
\text { not sufficient }\end{array}$ \\
$\begin{array}{l}\text { A4: Perceptions (A1-A3) are contextualised with regard } \\
\text { to past collective experiences with adversity that } \\
\text { underpin evaluations of future potential }\end{array}$ & $\checkmark$ & $\checkmark$ & $\begin{array}{c}\text { Both necessary } \\
\text { and sufficient }\end{array}$ \\
$\begin{array}{l}\text { A5: Aggregate of individual's beliefs of the team which } \\
\text { are shared among members in varying degrees }\end{array}$ & $\checkmark$ & $\checkmark$ & $\begin{array}{c}\text { Necessary but } \\
\text { not sufficient } \\
\text { A1 and A2 and A3 and A4 and A5 and A6 and A7 }\end{array}$ \\
\end{tabular}

